THE

MICROGRAPHIC DICTIONARY:

A GUIDE TO THE EXAMINATION AND INVESTIGATION

OF THE

STRUCTURE AND NATURE

oF

M I C R O S C O P I C O B J ECTS.

BY

J. W. GRIFFITH, M.D. \&C., MEMBER OF THE ROYAL COLLEGE OF PHYSICIANS;

AND

ARTHUR HENFREY, F.R.S., F.L.S., \&c., PROFESSOR OF BOTANY IN KING'S COILEGE, LONDON.

\title{
THIRD EDITION.
}

EDITED BY

J. W. GRIFFITH, M.D. \&C.;

ASSISTED BY

Tre Ret. M. J. BERKELEY, M.A., F.L.S.,

AND

T. RUPERT JONES, F.G.S.,

PROFESSOR OF GEOLOGI, ROYAL MILITARY AND STAFF COLLEGES, SANDHURST, ETC.

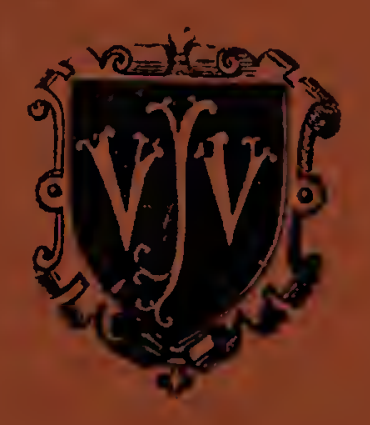

L O N D O N :

JOHN VAN VOORST, 1 PATERNOSTER ROW. MDCCCLXXI. 


\section{AN ALPHABETICAL LIST OF BOOKS PUBLISHED BY Mr. VAN VOORST.}

Many of the works are freely illustrated; and of some a few large-paper copies have been printed.

ACCENTUATED LIST OF BRITISH LEPIDOPTERA. $8 \mathrm{vo}, 5 \mathrm{~s}$.

ADAMS, BAIKIE, AND BARRON. MANUAL OF NATURAL HISTORY, for the Use of Travellers. Post 8vo, $12 s$.

ADAMS, H. AND A. GENERA OF RECENT MOLLUSCA. 3 vols. 8vo,

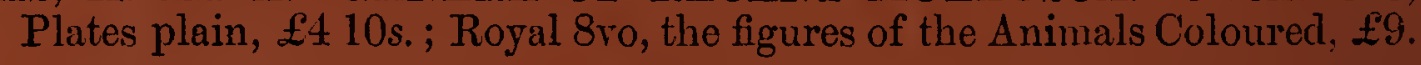

AIKIN. ILLUSTRATIONS OF ARTS AND MANUFACTURES. Foolscap 8vo, 8s.

ANSTED. ELEMENTARY COURSE OF GEOLOGY, MINERALOGY, and Physical Geography. Second Edition, Re-issue, post 8ro, $12 s$.

- SCENERY, SCIENCE, AND ART. 8ro, 10s. $6 d$.

- THE ANCIENT WORLD. Second Edition, post 8vo, 10s. $6 d$.

- THE GEOLOGIST'S TEXTBOOK. Foolscap 8vo, 3s. $6 d$.

- THE GOLD-SEEKER'S MANUAL. Foolscap 8vo, 3s. $6 d$.

ATTFIELD. CHEMISTRY: GENERAL, MEDICAL, AND PHARMAceutical. Second Edition, post 8vo, 12s. 6d.

BABINGTON. BRITISH RUBI. Fcap, 5 .

- FLORA OF CAMBRIDGESHIRE. 12mo, with a Map, $7 \mathrm{~s}$. 10s. $6 d$.

BAILY. CHARACTERISTIC FIGURES OF BRITISH FOSSILS. Parts 1 \& 2, 8vo, plain, 5s.; Coloured, 10s. each.

BAPTISMAL FONTS. A Series of 125 Engravings, with Deseriptions. 8ro, $£ 11 s$.

BATE AYD WESTWOOD. BRITISH SESSILE-EYED CRLSTACEA. 2 vols. 8vo, £3; Royal 8vo, £6.

BEALE. NATURAL HISTORY OF THE SPERM-WHALE. Post 8vo, 12 s. BECK. THE ACHROMATIC MICROSCOPE. Royal 8ro, 21s.

BEDDOME. ICONES PLANTARUM INDIA ORIENTAIIS. Parts 1-5, 6s. $6 d$. each.

- FERNS OF BRITISH INDIA. 4to, vols. i. \& ii., £4 each, and 3 parts, $6 s .6 d$. each.

BELL. BRTTISH REPTILES. Second Edition, 8vo, $12 \mathrm{~s}$.
BERNS OF SOUTHERN INDIA. 4to, in 


should be preserved in a wide-mouthed stoppered bottle, and its solution prepared when requisite, as it easily becomes decomposed by dust \&c.

Troughs are flat, oblong glass boxes, without lids. They are made of pieces of glass cemented together by marine glue, and are used in examining the larger aquatic plants or animals in a living state; also in mounting objects.

Divided Scale.-A metallic or ivory scale divided into 100ths, \&c. of an inch, is indispensable in micrometric admeasurements (see Measurenent). The metal or ivory should extend beyond the graduated portion.

Micrometer:-A glass slide with fine lines scratched upon it with a diamond, these being $\frac{r}{1000}$ th of an inch apart, is absolutely requisite. Another, with coarser divisions, is also required to be placed in the eyepiece, for making measurements (see Mrasurement).

A rectangular brass table, with two legs at one end and one at the other, is useful in macerating objects upon slides in chemical reagents, oil of turpentine, or Canada balsam, and in mounting objects. It is heated by a small spirit-lamp placed beneath.

Ring-Net.-A very useful piece of apparatus for collecting Desmidiaceæ, Diatomaceæ, \&c., where entangled amongst Confervæ, \&c., or forming crusts or films upon other aquatic plants, consists of a brass or wooden ring about 4 inches in diameter, furnished with a groove round its circumference, in which also a radial aperture exists, through which the end of a stick may pass. A piece of very fine muslin, rather larger than the ring, is then laid over it, and the margins of the muslin fixed in the groove by means of a vulcanized Indian-rubber band. Or this apparatus may be so modified, that the muslin is fixed by means of an inner ring, adapted to the outer, but incomplete at one point of its circumference, and with a projecting rim to prevent its passing through the outer ring. Thus we have a kind of strainer; and by using several pieces of previously wetted muslin in succession, a large number of the minute organisms may be separated from the water. The pieces of muslin may be brought home, folded up, in wide-mouthed bottles, separately, or several in one, according as the organisms are obtained from one or several waters. In this way we save carrying a large quantity of water. The pieces of muslin are afterwards opened and placed in jars of filtered river-water, and exposed to the light, when the organisms will become detached.

A simple microscope, or some apparatus which will allow of dissection with the aid of lenses, is essential, provided an erecting eyepiece or the erecting-glass (p. $\mathrm{xx}$ ) be not at hand. It is of little consequence which be selected, provided a large and firm sloping amin-rest be furnished on each side of the stage. Either doublets or the lower powers may be used. Some of the modern simple microscopes are binocular.

Leather Case and Collecting-Bottles.-The Diatomacer, Desmidiacex, and other smaller Algæ, as also the Infusoria, require to be collected and brought home in bottles. These should be of about 1 or 2 ounces capacity; and for portability without risk of being. broken, they should be packed in a case made of stout leather, with a separate space for each bottle. The whole will pack up in the form of a book. These are manufactured by Ferguson, of Giltspur Street.

Having given a slretch of the most important pieces of apparatus, we will say a few words upon the illumination.

Illumination.-The best light in general for microscopic purposes is undoubtedly daylight, or that of the sun reflected from the clouds; and this is certainly the light which can be borne for the greatest length of time without injury to the sight. The position of the observer is of importance; it should be such that the window is on his left hand, or even the back slightly turned towards the window. The advantages of this position are great; for then but little light will enter the eyes directly from the window, and it is of 
the greatest importance, during a microscopic examination, that the least possible amount of light should be admitted to the eye, from any source, besides that transmitted through or reflected from the object. In drawing also with the camera lucida this position should be strictly observed; for all extraneous light which would interfere with the distinctness of the image is thus excluded, and the shadow of the pencil and hand does not interfere with or obscure the sketch in progress, which would be the case if the observer's right hand were towards the window. But in daylight, the light entering the eye from the window, even in the position above mentioned, will interfere with the observation, unless a preventive be employed, which is to place a screen, either supported upon a stand or fixed to the upper part of the body of the microscope, between the eye and the eyepiece of the microscope and the light. This screen may be made of card-board or thin wood, covered with black velvet. If it be fixed to a moveable arnu, like the lens of the sidecondenser, it may be easily placed in any convenient position. If to be fitted on the microscope, it may be constructed thus: a piece of stout card-board, of about the size and shape of one of the plates of this work, should have the corners rounded off; and should be bent at a right angle at about the lower one-fourth; a hole being cut in the middle of the smaller portion, of a size just to fit the top of the body of the microscope, a short tube of card-board is then made by sewing or pasting, and this being fastened in the same way to the circular aperture serves to keep the screen in position. The whole is then covered with black velvet. When used, the long flap should be placed towards the left side; it then shelters the eye and upper part of the eyepiece from the light. A screen of this kind should always be kept upon the microscope, for it is of the greatest service. A tube made of a roll of card-board, fastened to the inside of the angle of the screen described above, will serve to fix it to the stem of the side-condenser; it may then be made to slide upon this axis or stem at pleasure. It is hardly possible to use the high powers of the microscope by daylight without a screen of this kind.

But few persons have the opportunity of using daylight for microscopic researches, and with the highest powers ordinary daylight is by no means sufficient; hence artificial light of some kind is called into requisition; and the most common source of this is an Argand lamp with oil. For ordinary purposes this answers well, although the best for examining Diatomaceæ, \&c., is a Paraffine-oil or camphine-lamp, especially when stops and very high powers and eyepieces are used, whereby a large amount of light is intercepted. In "Fiddian's lamp," the flame is enclosed in a metallic case, so resembling a bull's-eye lantern, the light escaping from a round orifice only; hence no extraneous light can reach the eye. The lamp must slide up and down the stem, so that it can be placed at any height; and it should be furnished with a shade, also moveable. A whitecloud earthenware shade has recently been recommended. Norman's paraffine-lamp, and Collins's Bockett lamp, with an attached bull's-eye, are good lamps.

Much of the success with which the structure of an object is displayed, will depend upon the manner in which the light is thrown upon or transmitted through it. In general the more light that can be condensed upon opaque objects the better; and when the various parts of sucl objects are of different colours, the more direct the light and the greater the angular aperture of the object-glass, the more clearly will the parts be distinguishable; while in certain opaque objects which present questionable elevations or depressions on their: surface, great obliquity of the incident light is essential. With transparent objects it is sometimes desirable to diminish the amount of light more or less; which may be done, either by means of the diaphragm, by using the flat instead of the concave face of the mirror, or by inclining the mirror to one side. It must not be forgotten, in determining 
the cause of the better display of an object by the substitution of a less amount of oblique light for a larger amount of direct light, that it need not necessarily arise from the obliquity; for in many instances the cause is simply the diminution of light, whether direct or oblique being a matter of indifference. When the mirror has only one reflecting surface, the amount of light may be diminished by removing the lamp to a greater distance from the mirror. But the difficulty usually found consists in the amount of light being too small instead of too great. This arises from bad management, and may be overcome by attention to the following circumstances: the mirror must be placed as near the lamp as possible; if it cannot be brought within a few inches of the lamp, the shallow bull'seye condenser must be made to condense the light upon the mirror: with the objectglasses of high powers the achromatic condenser must be used; and the lower the power of the condensing lenses, the greater will be the amount of light transmitted. The lined appearances presented by many objects, require for their exhibition very oblique light, which nuay be obtained by first raising the mirror as near as possible to the plane of the stage, and then bringing it as much to one side or the other of the stage as can be done; Amici's or Reade's prism is very useful for producing the same effect in a greater degree; large angular aperture in the object-glass is also very advantageous under these circumstances, because it will allow of the admission of rays of such a degree of obliquity as could not enter one of smaller aperture.

In cases where still more light is required than can be obtaine in any way by reflection from the mirror, this must be turned aside, and the direct light of the lamp used, thus: clamp the slide so that the object projects beyond that side of the stage which is nearest the lamp. The body of the microscope is then rotated so that the object-glass is over the object and fixed by the milled head; the axis of the body being then directed to the light, the object may be brought into focus; and by moving the lamp around the microscope, light of any obliquity may be made to pass through the object. This is a simple way of obtaining the most oblique light, and as the light comes directly from the lamp, there is no loss from reflection, as in the use of prisms. By a little variation of this arrangement, the light may be made to fall very obliquely upon opaque objects, especially if uncovered.

Nany years ago I suggested a method of remedying the defects of artificial light, or that ordinarily used to replace daylight. The well-known glare attending lamp- or candle-light, and the predominance of a yellow colour, so visible when compared with daylight, render it very unfavourable for microscopic purposes. It was proposed to mix some substance with the combustible which during its combustion evolved a light of the colour complementary to (or forming white light with) that predominant in the artificial light, or to pass the light in its passage from the artificial luminary through a piece of glass of such colour as to intercept or check the objectionable rays. As these rays are of a yellow or reddish-yellow colour, the colour of the glass must be blue, or purplish blue; but the exact shade must be obtained by experiment. Thus: the lamp, or whatever source of artificial light it may be, is lighted in the daytime, and the light transmitted through the microscope by reflection in the ordinary way, when its intensely yellowish colour is very obvious. Pieces of glass of different colours are then separately placed at right angles to the path of the rays from the lamp to the mirror, either close to the flane (in the form of an ordinary lamp glass), upon the face of the mirror itself, beneath the stage, or in an extra head of the side-condenser. If the glass be of the proper tint, and be placed at the proper distance from the light, and in the proper situation, the field will appear as white as the light of the clouds, which may be easily proved by altering the inclination of the mirror so as to reflect the light of the clouds and the lamp alternately. 
It may be remarked that the nearer the coloured glass is placed to the flame the less apparent effect will be produced, $i . e$. the more will the yellow colour be perceptible, and vice versâ. If the field still appear yellow, the glass is not of sufficiently deep colour; if it appear blue, the colour of the glass is too deep. The first method, or that of mixing some substance with the combustible (oil, tallow, \&c) capable of evolving a light of the requisite tint to form white with the yellow of the artificial light, would be far preferable to the latter metlod; but I am not aware that any experiments have been made to carry out this idea. It would have two great advantages, viz. that there would be no diminution of light, and that the entire apartment would be illuminated by a light equivalent to that of ordinary day. The second method has one objection, which is, that it intercepts a large quantity of the light, so that in the examination of those objects with high powers which require intense illumination, or where much of the light is arrested by stops, it is decidedly objectionable. The advantages which the use of the blio lass possesses are, that it softens the light very much, and that it enables the observer to discriminate between colours as in ordinary daylight.

A few years after the publication of the above metlod, a patent was taken out for the construction of lamp-glasses of a blue colour; but they are of little service, merely slightly softening the light, or intercepting a small proportion of the yellow rays.

The proper way would be to "flash" the properly tinted blue glass upon one side of a pale blue lamp-glass, so that by simply turning the glass round, the light might be transmitted through either of the differently coloured portions. Rainey's "Light-modifier" acts upon this principle. Numerous other pieces of apparatus and ingenious contrivances will be found described and mostly figured in Carpenter's 'Microscope, \&c.' 1868.

\section{II.-GENERAL METHOD OF DETERMINING THE STRUCTURE OF MICRO- SCOPIC OBJECTS FROM THE APPEARANCES WHICH THEY PRESEN'T UNDER VARIOUS CONDITIONS.}

Microscopic and histological appearance, structure, and analysus.-Before proceeding to this, let us define what is to be meant by the structure of a microscopic object. If we take a piece of the free end of the finger nail, and examine a thin transverse section of it under the microscope, we find it to present numerous shorter or longer dark and sonewhat irregular lines running nearly parallel to the surfaces. These appearances do not vary essentially whether it be examined in the dry state, or immersed in water or oil of turpentine.

But when it is moistened with solution of potash, and allowed to remain so for some time, or the slide is gently heated, it becomes entirely resolved into a number of nucleated cells; and by watching the gradual action of the potash, it is easily seen that the cells were originally flattened and arranged in layers, which layers produced the lined appearance mentioned above (see the article NAILS). Now which is to be considered as representing the structure of the nail? the first or the second of the above results? Undoubtedly the second. The expressions microscopic structure and histological structure are used very indefinitely, and often synonymously; but the former may very conveniently be restricted to signify the apparent structure as determined with the aid of ordinary niechanical means ; whilst the latter may designate the true structure in relation to development. It may at first sight appear very unnecessary to make any distinction between the two; but it is really very important, and many of the descriptions of the structure of bodies, given in books, refer only to their microscopic structure. 
The determination of the histological or true structure is often very difficult. Frequently a week or a month must be devoted to the determination of a single point. Take the instance of a hard structure-a piece of the skeleton of one of the Invertebrata. A few sections may exhibit cells, laminæ or fibres, according to the preconceived notions of the observer; whilst the histologist will not express an opinion until the inorganic matters have been removed by long maceration in acid, the calcareous salts thoroughly washed away, and attempts have been made to resolve the organic basis into its histological elements by appropriate means. This may require very many experiments to be made, and no mean knowledge of particular branches of science for guidance in the selection of appropriate agents requisite for their performance. We shall have frequent occasion to use the above words in the restricted sense; hence this should not be forgotten. The word analysis will have the same meaning as that generally attributed to it, the ultimate products being morphological.

A general method of determining the structure of objects can hardly be laid down, it must vary so greatly according to the nature of the objects and their size. The first point is to render them transparent, if not already so. This may frequently be done by immersion or maceration, if dry, in water, glycerine, or oil of turpentine. But the solvent power of the liquid must be borne in mind; for the organic principle aleurone was overlooked for years, from its being soluble in water, in which the sections of the albumen of seeds containing it were inmersed to render them transparent. Sometimes the aid of heat is necessary, and objects may even require to be boiled in these liquids, either upon a slide placed upon the brass table over the flame of a spirit-lamp, or in a small tube. Sometimes sections require to be made, and these treated in the same manner. If soft, their elements may be separated by the aid of needles; sometimes pressure will answer the same purpose.

When the object is very minute, it will frequently be desirable to examine both sides of it with high powers. Hence it must not be placed upon an ordinary slide, on account of the thickness of the latter, but must be supported upon, and covered by thin glass. The best plan is to keep a number of slides made of tolerably stout card, wood, or tin, each having a piece cut out of the middle. A thin glass cover, rather larger than the aperture, should then be cemented by marine glue or Canada balsam to one side of the slide; the thin glass cover is then applied as usual.

A great advantage of this method of temporarily or permanently mounting objects is that, the card-board being flexible, there is no fear of injuring the object-glass, even if it should come into contact with the glass cover. If the object be very small and its struc. ture very delicate, it must be crushed, so that some of the fragments may lie perfectly flat upon the slide. See also the article Preparation.

Thre points to be determined in regard to the different parts of an object, horvever, may be best treated separately.

The examination of a microscopic object must comprise:-a, the microscopic analysis, including, -1 , the form ; 2 , the colour ; 3 , the structure of the surface; and 4 , the internal structure: $b$, the histological analysis, in the sense already explained : c, the qualitative chemical composition: and $d$, the measurement.

\section{A. Microscopic Analysis.}

1. The Form.-a. This is usually judged of from the outline, as seen by transmitted light, and often erroneously. Where a low power is used, the upper surface of an object and its sides are mostly simultaneously visible; but under a high power, only those parts lying within a very limited vertical range, or in the same plane, are visible at one focus; and 
the parts lying in planes above or below this can only be brought into view by altering the focus: hence the views of objects under high powers correspond to views of transverse sections of the same objects made through various horizontal planes; and as the margins of objects are usually more distinct by transmitted light than the upper surface, spherical or rounded bodies frequently appear flattened. When several bodies of the same kind are visible in the field of the microscope, some will almost always be found lying upon their sides; and even when the objects are greatly flattened, some will mostly be found lying on edge, presenting the side view.

b. But as there may be uncertainty in regard to the relation of these bodies to each other, the only safe method in forming a conclusion is to cause them to revolve or roll over, so that all their aspects may be distinguished. This is in general easily accomplished: if the object be already immersed in liquid, the inclination of the stage will answer the purpose; or a little benzole, naphtha, alcohol, or some other volatile liquid in which they are insoluble, must be added. The currents produced by the evaporation of these will cause the objects, especially such as are near the edges of the liquid, to move in all directions, and their true form may be discerned. Sometimes moving the thin glass cover sidewise, the object being kept in view, will answer the same end.

c. In figures of microscopic objects, the side view should always be exhibited if possible; and if not, it should certainly be described.

d. In the case of crystalline bodies, or such as present angular edges, their angles should be measured with the goniometer, if their chemical composition be unknown.

2. The Colour.-The colour of objects should always be carefully described, and its cause accurately determined. It most commonly arises from,-1, partial absorption ; 2, the presence of pigment, or other colouring-matter; 3 , from iridescence; 4, from polarization, \&c.

(1.) The most common cause is a peculiar property by which a portion of the coloured rays composing the white light which falls upon or is transmitted through an object is absorbed, the remainder being reflected or refracted so as to reach the eye. On examining bodies thus coloured, with whatever powers, their substance is found uniformly coloured, and this colour is unchanged by their immersion in water or oil of turpentine, and is the same in transparent bodies by both transmitted and reflected light. This is commonly regarded as the proper colour of an object. Example: a crystal of blue vitriol.

(2.) - a. In many cases, however, although an object may appear to the naked eye uniformly coloured, on examining it with a high power, the colour, which in fact arises from the above cause, is seen to be confined to certain molecules or granules, whilst the general substance is colourless. These granules may consist of vegetable or animal colouringmatters, metallic oxides, \&c. The nature of these matters should always be determined, if possible, either by microscopic chemistry-micro-chemical analysis, as it has been called, - or by ordinary chemical analysis. When the colouring-matter is of organic nature, and when its composition cannot be determined, or it has no definite name, it is called pigment. Objects coloured by pigment, metallic oxides, or other colouring-matters, are best examined by direct (not oblique) transmitted light, and when immersed in either water or oil of turpentine. These liquids do not change the colour, nor destroy it unless the pigment be soluble in them; but by rendering the general substance of the object more transparent, they cause the granules to become more distinct. The colour is the same both by transmitted and reflected light. Example: a brown or black hair of an animal, as the mouse.

b. Sometimes bodies coloured by pigment or other colouring-matters appear under the microscope uniformly dyed, although the colouring-matter consists of an insoluble molecular or granular powder-as a white animal hair first macerated in solution of ferrocyanide of 
potassium and then in solution of perchloride of iron. Chemical means will alone distinguish this cause of colour from the first, by removing the colouring-matter from the colourless basis.

(3.) The colours of many objects vary according to the direction of the light transmitted through them, or are only visible by oblique light, and the colours are different by direct, and oblique light. These arise from decomposition of white light by either interference or refraction. For the sake of brevity, these may be designated colours from iridescence, because they mostly exhibit the brilliancy and transparency of the colours of the rainbow. The interference or refraction upon which they depend is ordinarily produced by irregularities of structure, frequently depressions or grooves, and sometimes cavities containing air, \&c. Objects exhibiting these colours, which are most brilliant by very oblique light and under low powers, when examined with a moderately ligh power by transmitted direct or but slightly oblique light, frequently appear more dull and less brilliant, often dark or black in parts; and when immersed in oil of turpentine or some liquid approaching in refractive power the substance of which they are composed, so that their irregularities become filled with it, the colours vanish. Hence colour, when arising from iridescence, can readily be disting uished from that arising from general absorption or from the presence of pigment; and when the colour of an object obeys the above law, it may be predicted that structural irregularities sufficient to account for its production will be found if properly sought for. Moreover these colours are not the same by reflected and refracted light, and they vanish under very high powers. They may be studied in the species of Gyrosigma; and those observers whose microscopes do not magnify sufficiently, or whose object-glasses liave not sufficient angular aperture to admit of the detection of the markings upon some of the Diatomacer or other bodies of similar structure, may be sure that they are present when these phenomena have been observed. We were thus led to search for them upon the valves of Melosira varians, and Borreri, species of Nitzschia, \&c., where they had not been previously detected; and there they are present. Again, the colours of the dried valves of the Diatomaceæ, many of which have a brown tinge, have been supposed to depend upon the presence of the peroxide of iron; but as this colour vanishes when the valves are immersed in oil of turpentine, independently of the fact that the valves do not present the same brown colour by reflected and transmitted light, and by direct and oblique light, which we have stated to be characteristic of the presence of colouring-matter, the colour cannot arise from this cause.

An example of iridescent colour arising from the presence of fibres, is found in the tapetum. Certain cases, referable to this head, require special notice. Thus it sometimes becomes a question whether a very minute red spot, visible in an Infusorium, Alga, \&c., is the optical expression of a minute vacuole, or a little depression filled with water, air, or other fluid of less highly refractive power than the substance of which the organism consists, or whether it arises from the presence of pigment. The point is easily decided: a practised eye will recognize the transparency of the colour where not arising from pigment, and its granular appearance where the pigment is present. If the substance of the object be soft, compression will frequently destroy the appearance when pigment is absent. Drying the object and then immersing it in oil of turpentine or other highly refractive liquid will do the same, whilst pigment will become even more distinct if present. Moreover, on altering the focus of the object-glass, the colour will be found to change, when not arising from pig'ment.

The colours of thin plates are so rare in microscopic objects, that we must refer to works upon optics for an account of them. They occur in the crystals found upon the surface of the scales of various fishes, the eggs and wings of insects, \&c. 
(4.) The colour arising from polarized light is noticed under ANALYTIC CRYsTALS, Dichroism, and Polarization.

The colours of objects examined by transmitted light are frequently rendered much darker, and colourless or coloured objects may appear dark or even quite black, from refraction or reflection of the light out of the field of the microscope. Thus powdered vermilion appears almost black; air-bubbles appear black at the margins or entirely black, \&c.: hence the importance of comparing observations made by both reflected and transmitted light; for neglect of this precaution caused the air in the hairs of animals to be mistaken for pigment. Milk-white opacity mostly arises from the presence of numerous molecules, granules, thin layers of liquid or other surfaces which reflect a large quantity of the light incident upon them, as in milk-where the reflecting bodies consist of the globules of fatty matter (butter),-white paper, tubercle, \&c.

3. Structurc of the Surface.- $a$. When an object is of comparatively large size, the structure of the outer surface is in general easily determined by examining it with reflected light, $i . e$. as an opaque object, illuminated by the Lieberkiihn or side-condenser; but when the objects are small, sufficient light cannot be thrown upon them with ordinary condensers; recourse must then be had to Brooke's reflector, or the opaque reflectors mentioned at p. xix.

b. The appearances presented must also be controlled by those resulting from the action of transmitted light. And here we meet with a difficult task, in accomplishing which, the following questions are constantly presenting themselves:-Do certain spots, lines, or other markings visible upon the surface represent elevations or depressions? Are they cavities in the outer portion or layer of the object? Are they foramina or holes? Are they granules of pigment, or rows of them? Do the lines represent a true lined structure, or are they optical illusions? Is the surface smooth and free from markings? The methods of answering these questions must vary so greatly, according to the nature of the object, its size, \&c., that it would be almost impossible to lay them down by rule. The following considerations, however, are of most importance.

c. In many cases where structural appearances are visible at the surface of an object, their true situation above or beneath the surface may be determined by raising the object-glass above the focus of the surface. On then carefully and gradually depressing the object-glass with the fine movement, the stucture first brought into focus is the uppermost. Thus, the inner surface of the under membrane of the elytrum of the stag-beetle (Lucanus cervus) is covered with very minute hairs projecting from the surface (Pl. 27. fig. 2). On placing: this with the inner side uppermost and adjusting the object-glass as just described, the hairs are distinctly brought into focus before the surface of the membrane. Hence they are situated upon the surface; whereas, had the surface of the membrane been brought into view before the hairs, it must have been concluded that the latter were situated on a plane below this. It may be stated that the surface of a membrane is recognized to be in focus by certain irregular granules, molecules, or wrinkles mostly visible upon it.

d. Frequently, when hairs, filaments, or spines project from a surface, their relative position may be determined by examining the margin of the object if it be rounded, or the margin of a fold if it be flat and membranous, - as in the case of ciliated bodies, Infusoria, \&c.

$e$. Cilia upon the surface of an object are sometimes so minute and transparent as to be with difficulty detected; they can however always be made evident, when present, by the following means:-1. Drying the object; they then become much darker from refraction. 2. Dyeing the object with solution of iodine; drying the object after the addition of the latter solution is sometimes advantageous. 3. Mixing insoluble coloured particles, as those of lampblack, with the water in which the objects are contained; of course this is 
only of use if the objects be living; the particles will then be set in motion, and their motion may be distinguished from molecular motion by the definite direction in which the particles move.

$f$. The nature of many markings, spots, \&c. is best determined by comparing at different foci the effects of the refraction of the transmitted light produced by the markings themselves, and the substances in which they are situated; and these phenomena may be conveniently illustrated by their occurrence in known objects. If a drop of oil of turpentine, which has been digested with alkanet root so as to become coloured, be placed upon a slide, a drop of water added to it, a thin glass cover applied, and the cover be moved backwards and forwards upon the slide with the finger covered with a cloth, the drop of oil will be subdivided into globules of various sizes, some of which will enclose globules of water; thus we shall have globules of the oil surrounded simply by water, globules of water enclosed in globules of oil, and some of these globules will contain within them globules of the other kind again, the globules of oil being readily distinguished by their red colour. On examining the slide with a tolerably high power, all the globules will appear bounded by a black circle, and present a luminous point in the centre, when viewed separately, and the focus suitably adjusted for eacl. But when they are examined in comparison and together, they will be found to exlibit characteristic appearances according to the variation of the focus. Thus, of the simple globules, when their margin is most distinctly brought into focus, some will become more luminous as the object-glass is depressed (Pl. 40. fig. 1 a) -these are globules of water surrounded by oil; others will become darker under the same circumstances (Pl. 40. fig. $1 b$ ), and very luminous as the object-glass is raised (Pl. 40. fig. 1c) -these are globules of oil; and the nature of the components of the compound globules may easily be determined by the occurrence of the same phenomena. The globules of oil, being more highly refractive than the water, act like little convex lenses; whilst the globules of water surrounded by the oil, exerting a lower refractive power than the latter, act like concave lenses, and their centre appears luminous because the rays which traversed them diverge as they ascend, as if they emanated from a (virtual) focus situated beneath the globules, or on the same side of them as the mirror. Hence these foci may be distinguished as the "lenticular foci " of the objects. And when dots or markings are very minute, frequently all that can be distinguished under the microscope are these lenticular foci of the various parts.

The same phenomena may be observed in air-bubbles immersed in water; these correspond with the globules of water surrounded by the oil. It need scarcely be remarked that the object in colouring the oil is to allow of the control of the conclusions arrived at.

g. In the globules of sarcode and many cells, the vacuoles are easily shown by the same method, to be filled with a material of less refractive power than the general substance of which they are composed; these vacuoles are frequently mistaken for nuclei and nucleoli, but they are readily distinguished from them by the dark appearance they present when the object-glass is raised above the focus of their margins.

$h$. The above principles are applicable to the determination of numerous cases where the elevation or depression of a spot or marking upon a surface is called in question; for elevations on a surface will produce the general effect of convex lenses, whilst depressions will produce that of concave lenses. In the above experiment, planoconvex lenses of both oil and water are frequently seen, and readily distinguished by the above means.

Take also the instance of a Paramecium aurelia, either dried or immersed in water. The surface is beautifully marked with pretty regular dots, which appear luminous as the object-glass is depressed (Pl. 25. fig. $1 a$ ), and dark as it is elevated (Pl. 25. fig. 13 ); hence 
they consist of depressions upon the surface. Had they been elevations or little tubercles, they would have become more luminous as the object-glass was raised, and vice versî.

When an isolated granule of pigment or of any opaque substance is brought into focus, on raising the object-glass a luminous spot appears to occupy its place; hence it agrees so far with a highly refractive granule. The appearance, however, arises from diffraction, and may usually be distinguished from that produced by refraction, by the luminous spot equalling or exceeding the granule in size, whilst in the latter it is smaller and more brilliant.

$i$. In all these experiments the less oblique the light the more certain will be the results. But this method is inapplicable to decide whether the less-refractive portions are simply depressions or cells. This may often be determined by examining the margin of the object where possible (as in Paramecium), and observing whether there are depressions upon it corresponding to the parts at which the dots are situated, and whether these depressions are continuous with the dots (Pl.25. fig. 1b). When the substance of the object is somewhat firn, drying it, if moist, will cause the dots to become filled with air; they will then, if cells, appear infinitely blacker than if simply depressions, and visible as readily by direct as by oblique light; and after the object has been moistened with water or oil of turpentine, if it be immediately examined, the blackness of the dots will appear still greater, and they will be distinctly visible by direct light; whilst depressions are much more easily filled with liquid, and then, if minute, will only be visible by oblique light.

k. If it can be shown that the parts corresponding to the dots are depressed below the general surface, and the dots or depressions present an angular outline, these dots cannot possibly represent cells; because, if the angularity of the outlines of cell structures arose from the pressure of surrounding or adjacent cells, this pressure would necessarily be exerted also upon the free or external portion of each cell, so as to render it convex, or at any rate not concave. The firmness of the substance of the object must be attended to ; because where it is absent, as the cells part with the liquid portion of their contents, the outer portion of the cell-wall may become approximated to the inner, and thus no space be left for the air to enter, as in the exuvir of a Triton for instance.

$l$. In brittle objects, as the siliceous valves of the larger Diatomacex, the examination of the margins of crushed and perfectly flat portions is important and sometimes conclusive ; for it may be found, as in Isthmia, \&c., that the depression of the object-glass requisite to bring into focus the margins of the thin depressed portion, is much greater than that required for the intermediate thicker parts. In the valves of the more delicate Diatomaceæ (Gyrosigma, \&c.), in which this observation is difficult to be made, the point is important that the line of fracture of the broken valves passes through the rows of dark dots or the lines corresponding to them, showing that they are thinner and weaker than the rest of the substance; had these dots represented elevations, the valves would have been stronger at these parts. The nature of the markings upon the siliceous valves of the Diatomacer, especially the species of Gyrosigma, has long formed a much-disputed point. In distinguishing in general minute points, as the little siliceous spines of the cuticle of Equisetum, the very short spines on the wings of many insects (Tipulide \&c.), or the minute spheroids in Schultze's siliceous films, it may aid somewhat to remember that prominences are usually most distinct under open central illumination, while depressions are most evident under the central-stop illumination. If we take a flat fragment of an Isthmia, and examine it by the aid of the condenser with a central stop and an object-glass of low power, care being taken that the condenser and stop are perfectly central, it will exhibit a series of angular dark or black dots bounded by luminous lines separating them (Pl. 11. fig. 47), and this when all parts of the object are best in focus; for when the object-glass is elevated or depressed, the whole becomes indistinct. The black dots in this instance clearly coin- 
cide with the depressed portions of the surface of the valve. On examining a fragment of the valves of a Gyrosigma strigosum or angulatum under a high power, for they are not visible under a low one, exactly the same phenomena are witnessed when the parts of the object in view are perfectly ffat and appear at their most distinct focus, the black dots being bounded by angular short continuous lines, giving them the appearance of being distinctly hexagonal. On inclining the mirror somewhat, so as to render the light transmitted through the object irregular or unequally oblique, the appearances will be reversed, a number of luminous dots resembling pearls (Pl. 11. fig. 46) being visible, bounded by dark spaces. These are the lenticular foci of the little knots formed by the union of the raised bars existing between the depressed portions of the valve. In Pl. 11. fig. 41 is a diagram of a portion of a valve of Gyrosigma angulatum, magnified to the enormous extent of 15,000 diameters, taken from a photograph lent us by $\mathrm{Mr}$. F. H. Wenham; and the same appearances may be seen under a lower power in a very large number of the Diatomaceæ. The black hexagonal dots in the latter figure correspond to the black dots seen in Isthmia, and represent the depressed portions of the valves. The article Diatomaces must be consulted for further details in regard to the structure of these valves, and the article Angular Aperture in regard to the changes produced in the appearances of objects by variation of the angular aperture of the object-glass, and of the degree of obliquity of the transmitted light. But we may remark here, that these dots must not be compared to cells, but to the depressions found upon the seeds of the white poppy, Paramecium, \&c., in which forms resembling those resulting from the mutual pressure of adjacent cells are present, but do not arise, so far as we know, from this cause.

$m$. No special remarks are required in regard to furrows, as these are only elongated depressions.

$n$. When ridges are present, these are frequently left projecting at the margin of a fragment; sometimes they project naturally; and it may readily be linown that they are thicker portions of structure, by their blacker margins and their exhibiting the characters of elongated convex or plano-convex lenses.

In some cases, the position assumed by confined portions of air, when the object is immersed in liquid, will denote the existence of ridges. Thus we have seen portions of air, accidentally confined between the surface of a scale of Lepisma saccharina and the thin glass covering it, assume an elongated form, being limited laterally by the ridges upon the scale (Pl. 27. fig. 3).

o. Foramina or holes are in general readily distinguished by their dark and defined margins, and the absence of colour when they exist in coloured structures; when existing in transparent colourless objects, the latter mostly exhibit minute irregularities, by which the presence of some kind of matter is indicated, whilst these are absent in the foramina. Where there is difficulty in deciding, the structure should be broken, if possible, and the margins examined. Sometimes the polariscope is of use; the general substance may polarize light, but of course the foramina will not do so. Charring the structure, or colouring it with reagents, if organic, will sometimes afford decisive proof.

Foramina cannot be mistaken for elevations on the surface, because they do not become more luminous as the object-glass is raised, after their margin has been brought most distinctly into focus; in fact the reverse occurs: hence they so far agree with depressions; but they differ from these in their luminous appearance with high powers, and their not being rendered more distinct by oblique light, but the reverse.

p. When the structure in which they are situated is somewhat thick, and they form rather tubes than foramina, as the axes of these can hardly coincide with the direction of the transmitted light, their orifices will appear dark or black; hence they might be mistaken for granules of pigment: immersion or maceration of the structure in oil of turpen- 
tine, however, will fill them, and cause the dark appearance to vanish, whilst pigment would still be visible. Examination by reflected light will also readily disting'uish the one case from the other. Also where this tubular structure is present, perpendicular sections will exhibit furrows, which may be recognized as directed above. In distinguishing. foramina, the higher the power employed the less is the difficulty.

$q$. It has sometimes to be decided, whether certain dark lines visible at the surface of objects, represent ridges or grooves, or whether they are illusory shadows arising from the passage of light through a structure furnished with depressions, granules of pigment, \&c. This must be done by examining the object when illuminated by reflected light, or a hollow cone of oblique rays, such as is obtained on using the achromatic condenser with the central stop; when thus illuminated, the lined appearance will vanish, and the true structure will become visible.

$r$. It often happens that objects, especially highly refractive bodies, appear surrounded or covered by a number of black lines, rings or annular lines, arising from diffraction, and it becomes an important question whether these lines represent cell-walls, rows of dots, \&c. When they arise from diffraction, they vary in number according to the obliquity of the incident light and the angular aperture of the object-glass; and when the condenser is used, they vary according to its adjustment, and at a particular adjustment they will sometimes disappear entirely. Hence in these cases the condenser should always be used, and the results obtained controlled by the effects of immersion in highly refractive liquids, and the means mentioned below.

s. A very ingenious method has been proposed and adopted successfully by Mr. Wenham, for exhibiting the form of certuin very minute markings upon objects. A negative photographic impression of the object is first taken on collodion in the ordinary way, with the highest power of the microscope that can be used. After this has been properly fixed, it is placed in the sliding frame of an ordinary camera, and the frame-end of the latter adjusted into an opening cut in the shutter of a perfectly dark room. Parallel rays of sunlight are then thrown through the picture by means of a flat piece of looking-glass fixed outside the shutter in such a manner as to catch and reflect the rays through the camera. A screen standing in the room, opposite the lens of the camera, will now receive an image, exactly as from a magic lantern, and the size of the image will be proportionate to the distance. On this screen is placed a sheet of photogenic paper intended to receive the magnified picture.

A portion of a valve magnified in this manner is represented at Pl. 11. fig. 41.

4. Internal structure. - We must be understood here as referring to the general structure of an object, $i$. $e$. whether it is solid or cellular, \&c.; and where an object is composed of an aggregation of similar parts, our remarks must be applied to these individually.

The first question arising is whether a transparent object is solid or semisolid and homogeneous, or whether it represents a cell, $i$. e. has an outer membrane or cell-wall and contents of a different nature. When objects possess an outer coat, its two margins are sometimes easily distinguishable on examination by transmitted light, especially when its thickness is considerable. But when the outer coat is thin, these are difficult to distinguish; recourse must then be had to other means than simple inspection; and these will vary according to the nature of the object, and especially the softness of its cell-wall. Sometimes crushing it may show clearly that the contents consist of a liquid with numerous molecules and granules, and that the cell-wall is thin and membranous; for the subsequent addition of water may separate and render both distinct. The most valuable test-method, however, is the production of endosmosis or exosmosis. If we take a cell with a soft and thin wall, and add distilled water to it, it will imbibe a certain quantity of it and become distended, and often the contents will become distinctly separated and visible within; 
whilst if a saturated solution of some salt, as chloride of calcium, be added, it will become wrinkled and collapsed. On treating a solid or homogeneous body with water, it remains unaltered, or perhaps swells slightly; but on treating it with the solution of chloride of calcium, no wrinkling or contraction occurs, and its appearance is unchanged. If the outer coat be firm and resisting, the chloride will not cause it to contract and wrinkle.

If there be two coats, the outer being firmer than the inner, the latter will be wrinkled and collapsed, whilst the former retains its shape; this is the ordinary occurrence in young: vegetable cells. The exosmotic effects of the chloride of calcium should be loolred for soon after its addition to the object, particular care being taken that it comes into contact with the object; for when solid or semisolid bodies are macerated for a long time in the saline solution, they will become contracted, and globules of sarcode will escape from them; but we believe that in all these cases there really exists a cell-wall, or a structure corresponding to it; hence by solid or semisolid bodies, we must be understood to mean those which differ from cells according to the characteristic action of exosmose.

It must be remembered that solution of chloride of calcium is a highly refractive liquid; hence it frequently renders globules so transparent that they are almost or completely invisible, and thus apparently dissolves them; sometimes also it really dissolves them. Moreover, many so-called unicellular vegetable organisms exhibit the contraction of the internal cell-wall or primordial utricle, from long maceration in water only, as is so frequently seen in the Desmidiacex "mounted" in water. An aqueous solution of iodine is also frequently useful in bringing to light the existence of an inner cell-wall, especially in vegetable structures, causing it to become wrinkled and collapsed.

Cells have not the tendency to fuse together or adhere to each other, which globules of sarcode or other glutinous solid or semisolid substances have.

If the object be brittle, crushing it will sometimes show its internal structure, by allowing the examination of the margins of the fragments.

Spherical or rounded solid bodies, when immersed in water or other liquids of low refractive power, generally present a much less distinct black margin than cellular bodies, or those with membranous walls.

The determination of the contents of an object furnished with an outer coat, must be made according to the foregoing indications. The contents often consist of liquid in which are suspended molecules and granules. If these exhibit molecular motion, the material in which they are suspended must be liquid. It sometimes becomes a question whether a body enclosed within another is central or lateral. This is readily determined by causing the body to revolve by inclining the stage of the microscope, when, if central and fixed, the enclosed body will retain this position; and if it be less than the cavity of the enclosing structure, positive indication will be afiorded that the latter is solid, or at least that it does not consist simply of an outer coat with liquid contents and the enclosed body. But if it be attached to the inner wall of the enclosing structure, the eccentricity of its motion whilst revolving will be evident.

The contents of microscopic bodies are frequently rendered distinct by the addition of reagents, and in some cases can alone be distinguished by their use; thus the nuclei of animal cells are at once made evident by the addition of acetic acid, \&c.

The micro-spectroscope is often useful in detecting small quantities of different substances (SPectroscope).

We frequently have to decide whether the interior of an object is solid or tubular. If it consist of a firm substance, drying it, if in liquid, will cause the evaporation of the liquid or other contents, and the entrance of air. A section of it will also show whether it is solid or hollow. The effects of crushing it should also be observed. 


\section{B. Histological Analysis.}

This consists in the resolution of the object into its coniponent morphological elements, and is usually effected by subjecting it to the action of various chemical reagents, continued maceration, \&c. It must never be attempted if inorganic matters be present in quantity, until these have been previously removed. The reagent used should be one which exerts a solvent action upon the substance of which the object is composed, the action being interrupted at a certain stage by the addition of water, \&c. In regard to those objects whose morphological elements have become altered by individual growth, \&c., histological analysis is of course useless; and the manner in which these have acquired their existing structure, can only be determined by tracing the gradual changes which their morphological constituents undergo, from the earliest period of their existence to that at which they form the object in question. This constitutes the study of development, or it might be termed Histological synthesis. It can rarely be followed directly; but can often be carried out indirectly by examining a number of the objects in all stages of their development, and comparing the changes undergone by their constituents. It requires special care in controlling the identity of the objects.

\section{Chemical Reactions.}

We cannot too strongly insist upon the necessity of investigating these in the case of all objects submitted to examination, the nature of which is at all doubtful,-and this because in many instances the form or general appearance will afford no criterion by which the nature may be determined. Judgment founded simply upon the form, or upon the mere inspection of an object, therefore, will illustrate the abuse and not the proper use of the microscope. The quantitative and ultimate analysis of substances cannot be made in any manner by the aid of microscopic manipulation; but the qualitative analysis, or the study of the action of chemical reagents upon the object or substance by the aid of the microscope, or the micro-chemical analysis, as the Germans style it (and the term is very convenient), may be undertaken with the prospect of almost certain success, in most cases at least, in ascertaining the proximate cliemical composition.

The characteristic reactions or tests for the various proximate principles are given in this work under the respective heads of those substances; and we can here give only a brief sketch of the manner in which the micro-chemical analysis of a substance may be conducted, and without which its microscopic investigation must be imperfect and of little or no value.

The first point to be attended to is, to ensure, as far as possible, the freedom of the object from foreign admixtures. Thus if it should have been found in an animal or vegetable liquid, it nust be carefully washed, either in a watch-glass or upon a slide whilst covered with thin glass. The former is readily accomplished: the substance being placed in a watch-glass, water or other solvent of foreign matters is added; the whole is then set aside, to allow of the subsidence of the substance, and the supernatant liquid removed by a pipette. If the body or the particles be very minute, it or they must be placed upon a glass slide, and covered with thin glass; the latter should then be pressed, so far as is possible without crushing the particles, but sufficiently to fix them, and a small piece of coarse white blotting-paper placed upon the upper surface of the slide, so as to touch the edge of the liquid. Capillary attraction will cause the liquid to be absorbed by the paper. Small quantities of water, or other proper solvent, are then added by small portions from the end of a glass rod to the opposite edge of the liquid confined by the thin glass. Thus a current will be set up, and the newly added liquid will be absorbed by the blotting- 
paper, washing in its course the particles confined between the two glasses. The current will be regulated by the quantity of liquid added, and the facility with which the paper absorbs it.

When the body has been washed, the effects of the various reagents may be examined, by the addition of them in small quantities from the conical stoppers of the test-bottles (see Test-box, p. xxiv). The test-liquid being applied to the edge of the liquid in which the body is immersed, gradually mixes with it, and the effects produced may be watched step by step. If a solvent or other action is seen to take place, the result is decisive; but if no action be evident, it must be remembered that the reagent added may not have reaclied the object under examination, perhaps from an insufficient lapse of time for the occurrence of diffusion in the two liquids. To be positive, therefore, that the reagent has no action upon the object when none is at first apparent, as much as possible of the liquid in which it is immersed should be removed by blotting-paper; or the liquid be gently driven off by evaporation; or, if the object be of sufficient size to ensure its not being lost, the thin glass should be removed, and the whole, or as much as possible, of the liquid removed either by the blotting-paper or evaporation. On then covering the object with the thin glass, and adding the reagent to the edge of the latter, there can be no doubt of its coming into contact with the body; and the result may be considered decisive.

Where the combined effects of a reagent and heat are required to be observed, the former may be added as usual, and the slide placed upon the brass table mentioned at $\mathrm{p}$. $\mathrm{xxv}$ until the liquid boils, or the requisite amount of heat has been applied,--the object, of course, being covered by thin glass. The slide must then be allowed to become perfectly cold before being placed under the microscope, otherwise the heat might melt the balsam with which the lenses of the object-glass are cemented together. The cooling is much facilitated by placing the slide upon a plate or surface of metal; we generally use the foot, or a part of the stand, of the microscope for this purpose.

The effect of a red heat is sometimes very desirable to be tested. This may be accomplished by exposing the object, placed upon a strip of platinum foil, a piece of thin glass or of mica, to the flame of a spirit-lamp. The odour evolved should be noticed. If this be ammoniacal, or resemble that of burnt horn, the body, if not crystalline, is probably of animal nature, and certainly contains nitrogen.

If the body consist solely of inorganic matter, or of oxalates, it will not be blackened by the heat. If it consist partly of inorganic and partly of organic matter, it will be blackened, and the inorganic matter will be left in the form of an ash. The alteration produced in the form of the object by the heat should also be noted.

In applying a red heat to substances upon thin glass, the whole of its moisture must first be expelled by evaporation; otherwise the glass will certainly crack, and the experiment be spoiled. The strip of platinum may be held by forceps; and the thin glass or nuica, upon a curved piece of iron wire. We can here add only a few of the reagents the action of which it may be most desirable to obtain in determining the nature of a doubtful body. Further particulars will be given under the heads of the various reagents, principles, and tissues, in the body of the work.

1. Solution of caustic potash (especially when heated).-The cell-walls of plants are not greatly affected; they retain their primitive form, only becoming somewhat swollen, whilst animal substances are mostly dissolved; chitine, however, is unaltered. The solution also possesses a remarkable power of separating many animal structures into their conponent cells, \&c. When cold, it separates proteine compounds from fatty matters, \&c. It also removes the foreign compounds with which the cellulose of the epidermal structures of plants is often imbued. 
2. Solution of iodine (in water) dyes most animal and regetable substances brown; renders also line brown; colours starch, certain cell-walls of vegetables, amyloid, the amylaceous bodies of the human brain, \&c. blue.

3. Sulphuric acid, when added to the external coat or cell-wall of plants (cellulose) dyed with iodine, renders it blue or purple. In a few instances, however, where cellulose exists in animal tissues, the same blue colour is produced; but in these there is real animal matter also, recognizable by its appropriate tests. When added to bile or proteine compounds mixed with solution of sugar, it renders them red (Pettenliofer's test). If the body contain lime (except already as sulphate), the acicular crystals of the sulphate are produced.

4. Muriatic acid with heat colours the proteine compounds.

5. Acetic acid brings into view the nuclei of animal cells and tissues, dissolves many salts, \&c.

6. Dilute nitric acid (20 per cent.) coagulates albumen, renders unstriped muscular fibre-cells very distinct, \&c. Strong acid by boiling removes all but the cellulose from woody fibre.

7. Millon's test-liquid for proteine compounds. (See MrLon's Test.)

8. Ether or benzole dissolves fatty and resinous matters, \&c.

9. Chromo-sulphuric acid, or a mixture of solution of bichromate of potash and excess of sulphuric acid, dissolves the intercellular substance of plants, thus isolating beautifully the wood-cells \&c., and developes the starch-rings \&c.

10. Ammoniuret of copper, formed by digesting copper turnings in an open bottle with solution of ammonia, rapidly dissolves cellulose. It must be used fresh.

11. Dye-tests.-Carmine and ammonia, or the aniline-compounds (Judson's dyes), are often used as such (Drervg).

These are perhaps the most common reagents which the experimenter will be called upon to use. A general plan for the qualitative analysis of substances must be obtained from works upon chemical analysis. It may be renarked, however, that the qualitative analysis of portions of a substance too minute to be more than barely discerned by the naked eye, may be effected by the aid of the microscope. The use of the microscope in strictly chemical investigations also, cannot be too highly recommended; for it will frequently throw great light upon the distinction of chemical precipitates of closely approximative chemical properties.

\section{Measurement.}

A knowledge of the size of objects is of the utmost importance, and is frequently of great assistance in the distinction of one object from another' for many objects of totally dissimilar nature present exactly.or nearly the same appearances when examined with different powers. The dimensions should invariably be added to the description of microscopic bodies; and when figures are given, the number expressing the linear amplification of the objects should be placed near thent.

Directions for determining the measurement of objects are given under the head Measurement. It should always be expressed in fractions of an English inch.

In conclusion, we must remark that the observations given in this Introduction are not offered as by any means complete. However, we trust they will serve to show those who have not kept their eyes for many years upon subjects connected with microscopy, tliat numerous means are at their command for determining the structure of objects, to indicate the nature of these means, and that microscopic researches should be carried out upon something like a definite plan. 
sist. When the adulteration consists of a chemical substance as it might be called, i.e. a salt, metallic oxide, proximate principle, \&c., its nature is readily determined by chemical analysis; but when it consists of a vegetable tissue, which has been perhaps subject to a partly chemical process of manufacture, the judgment must be based upon the form of the various parts, their size, relative position, and other particulars holding a place in the Table already alluded to.

The following' list of adulterations of articles of general consumption will serve as a guide to the inquirer, and as an index to the special articles in this work in which further details will be found.

ARRow-ROOT.-Cheaper linds of starch.

BREAD.-Mashed potatoes, bean-flour, rice, alum.

Carenne Pepper.-Ground rice, mustard husks, deal sawdust, mineral colouning-matter of lead and mercury, \&c.

CHICORY.-Roasted flours of corn and beans, acorns, mangold-wurzel, parsnips, carrots, sawdust, mahogany, burnt sugar, red ochre, \&c.

Cinnamon.-Flour of grain and potato, cheap starches, \&c.

Cocos and Chocolatr. - Árrow-root and other starches, flours, sugar, chicory, red ochre, \&c.

CoFFEE.-Chicory and its adulterations, as above.

CURRY POWDER.-Flour, ground rice, red lead, red ochre.

Flour.-Meal of otler grains, beans, potato-starch, rice.

Ginger.-Flours of various kinds, mustard husks, cayenne pepper, turmeric.

IsIngLass.-Gelatine from bones.

LARD.-Potato flour.

Mustand.-Flour, turmeric.

OAT-MEAL.-Barley-meal.

Pepper and other spices. Flours of grain, peas, potatoes, \&c., ground mustard, linseed, \&c.

Prcrues.-Dilute sulphuric acid (vitriol) instead of vinegar.

Sugar.-Potato flour, starches.

TEA.-Various leaves, catechu, mineral colouring-matters, iron-filing's, rice husks.

Tobacco.-Various leaves, paper, \&c.

BIBL. Ure,Dict. of Arts and Manufactures; Mitchell, Adult. of Food; Normandy, Handbook of Commercial Analysis; Schacht, Prïf. d. im Handel vork. Gewebe, 1853; Wiesner, Mikroskop, \&·c.; Angus Snith, Rep. of Man- chester Sanitary Association, 1863; Hassall, Food and its Adult., London; Parliam. Rep. on the Adult. of Food, Drink, and Drugs, 1855; and Adult. detected, 1857 ; Odling, Journ. Soc. Arts, 1858, vi. 318; Garnier and Harell, Fulsificat.d. Subst. Aliment.; Pereira, Materia Medica; Sorby on Spectroscope, in Qu. Mic. Jn. 1869, p. 358.

ACID'IUM, Persoon.-A genus of Uredinei (Coniomycetous Fungi), consisting of numerous parasitic fungi infesting leaves and herbaceous stems, appearing in their full-grown condition as little cups filled with a reddish or brownish powder (spores), formed by a raising-up and bursting of the epidermis by the parasite developed within. Many may be detected in earlier stages by the deformities they produce in the growing structure of the plants infested, or by pale or reddish spots on the green surface, arising from the presence of the imperfect fungus underneath. These plants are commonly known under the name of blight, brand, \&c. Their history has recently received much elucidation at the hands of Tulasne, De Bary and others, and they are found to exhibit a more complicated organization than was formerly imagined. The organs of fructification are produced in two forms, berring great resemblance to the conditions lately ascertained to exist generally in the Lichens. A brief account of the natural history of certain of the species, derived from De Bary and Tulasne, will give a general idea of the character of this genus.

The nascent Aicidia are observed as minute spots upon the herbaceous parts of the plants which they infest. When sections are made of these and placed under the microscope, it is found that the parenchyma of the plant is deformed, irregular, and interrupted by large intercellular passages, among which ramify the filaments of the mycelium of the fungus; these are delicate, muchbranched and septate, about 1-3600 of an inch in diameter. At certain points these filaments are crowded and interwoven into hollow globular conceptacles, about 1-180 of an inch in diameter, immediately beneath the epidermis, the interior of which conceptacle is lined with delicate filaments (about 1-12000 of an inch in diameter) arising at all parts and converging towards the centre, except at the upper part, (which is open, and only shut from the external air by the persistent epidermis of the nurse-plant,) where they are directed upwards. A gra- 
nular mass occupies the centre of the conceptacle, separating the converging filaments from each other. By the growth of the upper filaments and the increase of the central granular mass, the whole structure increases in size, so as to push the epidermis up above the surrounding surface, finally bursting it, when the upper filaments ( $p a-$ raphyses) grow out through the orifice and form a little funnel-shaped tuft on the summit of the protuberance, through the middle of which the granular mass formed below makes its escape. These bodies may be found commonly on the spurges ( $A E$. Euphorbia), the barberry (AE. Berberidis), nettles (AE. Urtica), Compositæ (AE. Compositarum), \&c., early in the season; later, they may frequently be recognized in a dried-up condition, being forerunner's of the true sporiferous bodies (Pl. 20. fig. 1). The name applied to these organs is spermogonia. The filaments converging into the centre of these, termed sterigmata (Pl. 20. figs. 2,3, st), are the important parts of the structure; they terminate in rows of minute bodies of oval form, about 1-6000 of an inch long and 1-12000 in diameter (ibid. s p.), which become detached and separated, falling loose into the cavity, where, by a continued growth and shedding of similar bodies from the converging filaments, they accumulate to form the granular mass above spoken of as existing in that situation. The number ultimately becomes enormous, and a gelatinous substance is secreted, glueing them into a mass. When placed in water inder the microscope, or when wetted by rain in its natural position, the ripe mass swells and is protruded through the orifice of the spermogonium on the surface of the leaf. By a longer action of moisture the jelly dissolves, and the minute bodies (spermatia) spread about in the water, exhibiting " an oscillatory motion, as of a body attached at one extremity." De Bary states that he found iodine arrest this motion, while it persisted for some time in solution of chloride of cal-. cium. No cilia can be detected. Fresh spermatia were coloured bright purple red by sugar and sulphuric acid, but at the same time were so acted on that it could not be made out whether they possessed a membrane free from nitrogenous matter. Solution of potash renders invisible the outlines, not only of the spermatia, but of the sterigmata and paraphyses. The resemblance of these bodies to the spermatia of the Lichens (see Lichens), is too evident to be mis- taken; hence the same terms are applied to the corresponding organs.

The spermogonia occur either in regular groups or scattered just like the perithecia; when the latter are on the same surface of a leaf, they often form a circle round the former. Frequently they burst through on opposite sides of a leaf, and then the spermogonia are oftenest on the upper, the perithecia on the lower face (Pl. 20. fig. 1 sp).

After a number of spermogonia have been successively developed and discharged their spermatia, the mycelium, from which they originated, produces a new globular body formed of densely interwoven filaments, usually in the interior of the substance of the leaf or stem, not immediately beneath the epidermis, and ordinarily colourless. Increasing in size in all directions, this globular body, the perithecium, soon presents at its base, i. $e$. the point furthest from the nearest epidermal surface, another body composed of very numerous free-ending filaments enclosed in a cellular membrane, which body rapidly grows up within the perithecium, in the direction of the surface of the leaf or stem. The filaments, at first very delicate, are crowded very closely together, and each exhibits in its interior a row of short, colourless, roundish cellules, the uppermost of which is always the largest and the most advanced in development. These cellules are the spores, and the filaments in which they are found are the sporangia or theca. The membrane enclosing the sporangia, the peridium of Persoon, grows pari passu with them, and is composed likewise of rows of cells, which stand in a circle around the sporanges, but are firmly connected together side by side by an intercellular substance; this membrane closes in like a bell or vault over the sporanges. By the reciprocal pressure of all parts, the cells of this membrane, at first spherical or ovate, become polygonal. At a certain stage the apex of the perithecium gives way, so that it forms a lind of cup around the membrane enclosing the mass of sporanges arising from the base. The whole structure has by this time come immediately up to the underside of the epidermis, which is next ruptured, and the perithecium and the sporanges are protruded, more or less, according to the habit of the species (Pl. 20. fig. $1 p, p)$. The upper portions of the rows of cells composing the peridial membrane then separate more or less from each other, splitting into lobes, so as 
to set the sporanges free, and form a kind of cup with toothed margins seated in the expanded peritheciun (tigs. $6 \& 6 a$ ).

\section{Acidium Compositarum, Nart.} Fig. 6.

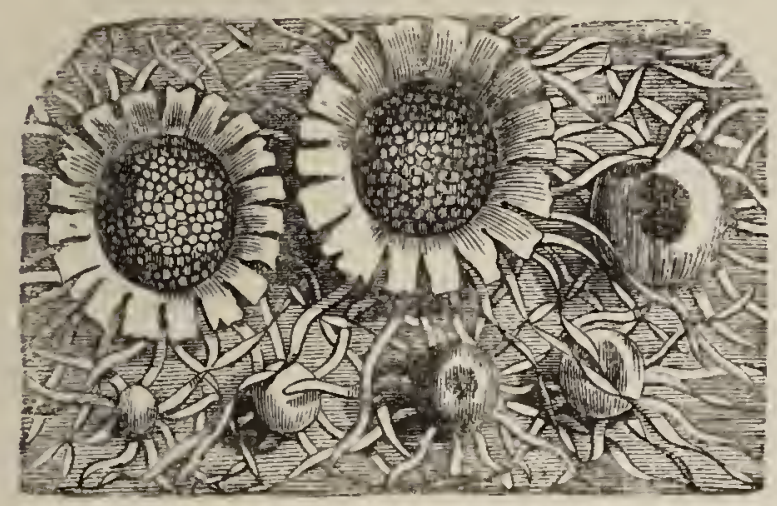

Peridia in various stages of growth on the surface of a leaf: 30 diam.

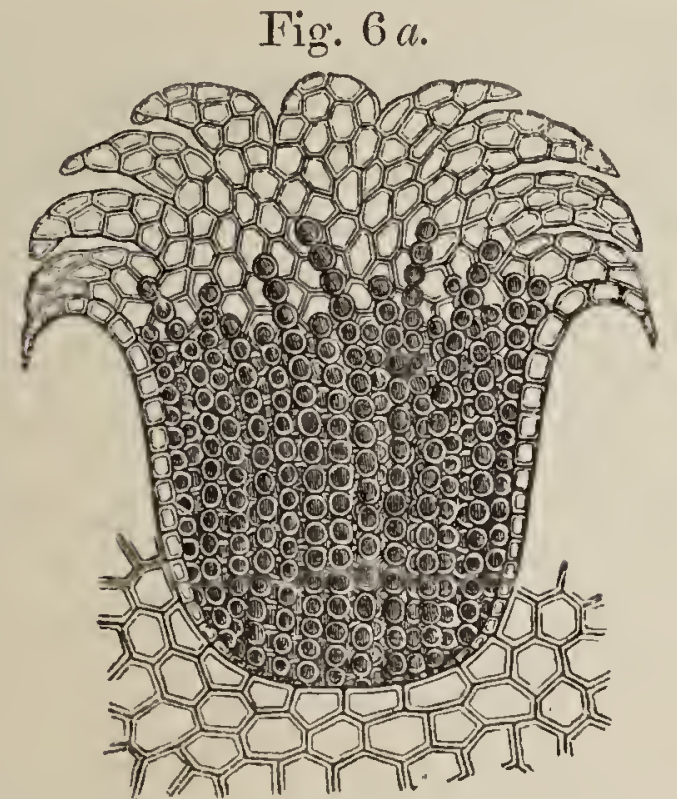

Perpendicular section through a burst peridium, showing the sporanges contained in it: 100 diam.

The spores, which are at first delicate cellules, subsequently acquire a tough membrane, increasing considerably in size, so as to distend the parent utricle or srorange, which is ultimately only recognizable where it connects the spores together in a moniliform series. The spores in most cases now acquire a deeper colour (except in AE. leucoconium), owing to contents chiefly accumulated in the centre. Their membrane is colourless, their form finally irregularly polygonal, and the diameter varies much, even in ripe spores of one and the same species, from 1-1000 to 1-1800 of an inch. The upper spores are often ripe at an epoch when young spores are still in course of production at the lower end of the sporanges; finally, however, the development ceases below and the tube elongates a little beneatl the lowest spore, forming a kind of pedicle or basidium to the row. The ripe spores either soon fall apart and fill the cup as a loose powder, along witl short incomplete sporanges, or the rows persist even after they are mature, held together probably by a firmer sporangial membrane.

The British species of Acidium are numerous; more than thirty are described by Berkeley in the British Flora, many of which are common, especially those of the Mints, the Composite, such as the Coltsfoot, \&c., the Barberry, the Gooseberry, Buckthorn, Spurge, Nettle, \&c. (AE. Compositarum, Menthe, Berberidis, Grossularia, crassum, Euphorbia, Urtica, \&.c.).

There is some reason to believe that Acidic are merely forms of certain Puccinice, therefore that the notion of the connexion between the Barberry-bush and Mildew is not purely imaginary.

Brbl. For Species:-British Flora, ii.pt. 2. p. 369 ; Greville, Sc. Crypt. Flora, pls. 7, $62,97,180,209$.

For Anatomy and Physiology:-Unger, Die Exantheme, pp. 297, 300, t. 3. f. 18, 19, t. 4; Neyen, Pflanzenpathologie, pp. 143, 148-50; T'ulasne, Comptes Rendus, March 24 and 31, 1851; Ann. des Sc. Nat. sér. 3. t. xv. ; ibid. sér. 3. t. vii. p. 45 ; sér. 4 . t. ii. pp. 126, 173; Léveillé, Rech. sur le dév. des Urédinées; Ann. des Sc. Nat. sér. 2. t. xi.; Corda, Icones Funqorum, iii. t. 3. f. 45; Anton de Bary, Die Brandpitae, Berlin, 1853, p. 55 et seq. pl. 5, 6 and 7 .

AGERITA, Persoon.-A genus of Stilbacei (Hyphomycetous Fungi) characterized by short necklace-like threads consisting of irregular spores produced from flexuous, branched, radiating sporophores, forming a subglobose mass. $\mathscr{A}$. canclida, Persoon, grows on damp twigs in marshy places, consisting of scattered white grains about the size of a poppy-seed. ZE. setosa, Grev., belongs to the genus Volutella.

Bibl. Greville, Sc. Crypt. Fl. pl. 268. fig. 1.

AGYRIA. - A genus of Infusoria $=E r$ vitia, Duj. E. legumen = Erv. legumen, D . Three other species.

Brbl. Claparède and Lachmann, Infus. \&c. i. p. 288.

ANGSTRE'MIA, Br. and Sch.-A genus of Leptotrichaceous Mosses, including many Dicrana, and Ceratodon cylindricus, Br. \& Scli.

Bibl. Müller, Synops. Musc. i. p. 426; Wilson, Bryolog. Brit. pp. 72, 85. 


\section{AËRIAL ROOTS.}

A ̈̈RIAL ROOTS.-A very large proportion of the exotic Orchids are epiphytic plants and produce aërial roots, which absorb moisture from the atmosphere; the same structure occurs in many tropical Aracex. The surface of these aërial roots is clothed by a peculiar tissue, formed of cells containing a delicate spiral fibre upon the wall (Pl. 39. fig. 6). The strata of spiralfibrous cells are sometimes numerous, and they cover up the true epidermis of the root. The growing points of such roots are green; but the spiral-fibrous cells soon come to contain nothing but air, and then assume a silvery-white colour.

ATTLA, Lamx. See Anguinaria.

ATHA'LIUM, Link. A genus of Myxogastres (Gasteromycetous Fungi). The common AEthalium, AE. septicum, L. (flavum, Grev.), occurs frequently on tan in hothouses, where it is very injurious, from the rapidity of its growth and the abundance of its spores. The ordinary form is yellow; but violet and reddish-brown varieties have been met with. It grows also on mosses in woods. Other species of Athatium have been found growing upon iron, lead, or other mineral substances; sometimes a few hours only, after they have been heated, so that the appearance seems quite marvellous. The cream-like matter, of which the part answering to the mycelium or allied production in other Fungi consists, exhibits Amoba-like movements.

Bibl. Greville, Sc. Crypt. Flora, t. 272; Sowerby's Fungi, t. 399. fig. 1 (as Reticularia hortensis, Bull.), figs. $3 \& 4$ (as R. carnosa and R. cerea); Bolton, Brit. Fungi, t. 134 (as Mucor septicus, L.); Berkeley, Crypt. Botany, pp. 236, 339.

AGARICINI.-An order of Hymenomycetous Fungi, comprising a great portion of the more important esculent species, characterized by an inferior hymenium spread over distinct gill-like processes, which are often easily divisible into two plates. In a few species the interstices of the gills are traversed by veins so as produce the semblance of pores. Amongst the more obscure species of the vast genus Agaricus, the hymenium is at first superior, but finally becomes inferior by the turning over of the pileus, which is attached at one point only, or by a very short stem.

'The hymenium is composed of vertical cells, called basidia by Léveillé, sporophores ky Berkeley. These bodies are elliptical or elongated cells growing out from the surface

\section{AGARICUS.}

of the lamellæ, with four slender stalk-like processes at the upper end, each bearing a single spore, which becomes detached when ripe. These basidiospores are observed by means of cross sections of the lamellæ; the sections must be very thin, and require a high power for satisfactory observation. The sections keep tolerably well put up in chloride of calcium, and are most instructive when taken from a series of specimens of different ages. See Agaricus, BasidioSPORES, and Hymenomycetes. The bodies called cystidia or pollinaria, are globular or oval cells, found associated with the basidia, containing granular matter exhibiting molecular motion when discharged. These organs have been supposed to represent antheridia, but are more probably paraphyses or abortive basidia.

BIBL. Berkeley on the Fructification of Hymenomyc. Fungi, Ann. Nat. Hist. vol. i. 81; Léveillé, Sur l' Hymenium des Champignons, Ann. des Sc. Nat. 2 sér. viii. 321; Hoffmaun, Bot. Zeit. xiv. p. 137 (1856).

AGA'RICUS, Linn. - A genus of Agaricini (Hymenomycetous Fungi). This is one of the largest genera in the Vegetable Kingdom, comprising not only a multitude of European species, but many from tropical climates. As it is of great importance in an alimentary point of view, it seems desirable to give a sketch of the principles on which the species are arranged. Many attempts have been made to divide it into genera, but with little success; and even the subgenera are not always satisfactory.

Undoubtedly, after separating those which are of a dry corky or coriaceous nature with those which in decay run into a sticky liquid, as the genus Coprinus, the first grand distinction depends upon the colour of the spores, which are white, rose-coloured, brown, purple brown or black. These characters, however, must be taken with a little latitude; amongst the white-spored species a few will be found where there is a slight pinky or dingy tint, but a very little experience will overcome the slight difficulty; in the rosy-spored series there is little distinction as to colour, but the spores are sometimes quite even in outline, sometimes distinctly angular, a form which very rarely indeed occurs elsewhere. Under the term brown are included various tints as there is a greater admixture of red or yellow.

As regards the two remaining series there is no difficulty. 
Another important distinction rests on the circumstance whether the gills are absolutely distinct from the stem, and again whether from an early stage of growth they are truly decurrent; but it is possible to carry the distinction of the decurrence of the gills too far, as in $A$. furfuraceus, which it has been proposed to place in a distinctsubgenus; the gills are sometimes decidedly decurrent, sometimes not at all so.

A third important distinction depends on the character of the general envelope, whether more or less distinct. That of the presence or absence of a ring is of less importance, as undoubted examples of $A$. melleus occur in which there is no ring, though every other particular, including the peculiar astringent flavour, accords. For the characters of the subgenera themselves, we may refer to the valuable works of Fries and to Mr. G. W. Smith's 'Clavis,' where, however, it is the opinion of the writer of this article, in which he is borne out by the prince of mycologists, Fries, that some of the subgenera rest on insufficient grounds.

As an article of food the esculent species have been too much neglected, and it is to be regretted that no sufficient analysis has at present been made of the more important species.

See Mushroom and Spawn.

AGATE.-The term agate is specially applied by geologists to the crystalloid concretions and geodes of chalcedony-quartz formed in the steam-holes and the fissures of volcanic rocks. It consists, chemically, almost entirely of silica, coloured by metallic oxides. But the principal microscopic interest lies in the so-called moss-agates or Mocha-stones, which are probably highly altered sponge-masses from the chalk and greensand. These, with the flints, have been especially examined by Bowerbank, who supposes them to have originated in the continued attraction and solidification by sponges, of silica dissolved in the water of the ancient ocean, - these sponges formerly existing at the bottom of the sea in as great abundance as their recent types are now found in the ocean, both in tropical and temperate climates. The spicula of spouges are commonly found; also very frequently the fibres, sometimes in a perfect state of preservation, but usually presenting the appearance of having suffered to a great extent from maceration and disruption of their component parts previous to fossiliza- tion. Generally the fibres adhere together in confused masses, presenting a moss-like appearance, with here and there one or two in a better state of preservation, and occasionally, near the outer surface of the mass, small portions of the tissue are found quite perfect; in other parts all the intermediate states between perfect preservation and nearly complete decomposition may be observed. The siliceous matter in which these remains are imbedded, usually presents a clear and frequently a crystalline aspect, while the remains of the organized mass are strongly tinted with colours: bright red, brown and ochre-yellow prevail; but occasionally the fibres are milli-white, or bright green. Sometimes the interior of the tubular fibre only is filled with colouring-matter, whilst the sides are semipellucid or of a milky white; in others the whole of the fibres are impregnated with it. Pl. 19. fig. 14 represents sections of a piece of a moss-agate, showing the silicified fibres of sponge $a$, the gemmules $b$, a separate fibre at $c$, and spicula at $d$.

There are two distinct points connected with the presence of these supposed organic remains in agate; one is, whether they really are organic remains, and the other is whether they are related to the formation of the agate, or merely accidentally present. The first point is a very difficult one; we have only the microscopic appearance of the bodies under one set of conditions to judge from: this is always very unsatisfactory; many of the appearances most peculiar to organic bodies, especially when the latter are not connected so as to form a tissue, can be closely imitated by crystallization. Still the mass of evidence is decidedly in favour of the appearances really representing portions of sponges.

The supposed vegetable structures of agates described by Turpin, Miiller and many others, have been clearly shown by Göppert to be entirely inorganic products, chiefly dendritic deposits of oxide of iron. His essay contains an elaborate history of the strange notions which have at various times been propounded concerning these objects. Sometimes agate contains crystals of quartz, carbonate of lime, or other mineral matters imbedded in its substance. Those paler varieties of quartz which consist of concentric layer's of radiately grouped crystalline needles, frequently polarize light very beautifully; the fortification-agates are common and elegant objects. 
BisL. Bowerbank, Trans. Gcol. Soc. 1840 (Ann. Nat. Hist. vol. vii. 1841 ; vol. x. p. 9 and 84); Toulmin Smith's objections (but they refer rather to flint), Amn. Nat. Hist. vol. xix. p. 1 and 289; Göppert, On the plant-like bodies enclosed in Chalcedony, Ratisbon Flora, 1848, p. 57. See Flint.

AGA'THISTE'GIA, D'Orb.-An order of Foraminifera in D'Orbigny's classification (1825). It may be said to comprise Cornuspira, Mitiola (subgenera, Uniloculina, Biloculina, Triloculina, Quinqueloculina, Spiroloculina, Cruciloculina), Hanerina, and Fabularia, members of the family Miliolida as established by Carpenter. The peculiar ball-of-thread-like folding of the segments, whence the name, is constant in the three last-named genera; but in Cormuspira it is merged in a discoidal spire at an early stage of growth.

Brbl. D'Orbigny, Foram. Cuba, p. 145 ; Foram. Canaries, p. 140; Foram. Americ.p. 68; For. Foss. Vienn. p. 255; Williamson, Rcc. Brit. Foram. p. 78, \&c.; Carpenter, Introd. Foram. p. 66.

AGLAOPHENIA, Lamx. (Pfr.).-A genus of Polypi, of the family Plumulariadæ. It consists of Phumuluria cristata, myriophyllum, pcrnatula (Jolınston). See Plumularia. 284.

Bibl. Hincks, Brit. Hydroid Zooph. p.

AGA'VE. See Fibrous Structures.

AG'RION.-A genus of Neuropterous Insects. See LIBELLULID ж.

AINACTIS, Kiitzing.-A genus of Oscillatoriaceous plants growing on stones in water. The two known species have been found in Britain.

1. A. granulifera. Fronds from 1-12 to $1-2$ " in diameter, often confluent, formed of repeatedly dichotomous filaments, dark olive green, containing separate particles of carbonate of lime. Rivularia granulifer $a$, Carm. Hassall, Brit. Fr. Algce, 1xv. 1. 4; Ainactis alpina, Kütz. Tab. Phyc. vol. ii. pl. 63. 1.

2. A. calcarea, Kütz. Fronds 1-4 to 1-2" in diameter, orbicular, convex, ultimately confluent, sometimes greenish, often dark chestnut, composed of dichotomous filaments, at length incrusted continuously with carbonate of lime. Kuitzing, l.c. pl. 63. ii.; Rivularia calcarea, Carmicliael; Lithonema calcarea, Hassall, l. c. tab. 1xv. fig. 2.

Kuitzing states that the gelatinous sheaths of the filaments of $A$. alpina have a spiral fibrous structure. See SpIral StrucTURES.
AIR.-It need scarcely be remarlied that the air consists essentially of a mixture of two gases, oxygen and nitrogen, in the proportion by volume of about 21 parts of the former to 79 of the latter, witl variable quantities of gaseous carbonic acid (about 1-2000th) and aqueous vapour. Now as the component molecules of gases are invisible with any powers of the microscope, the air possesses no microscopic characters. In two respects, however, the study of the air in its relations to the microscope is of great importance:-1st, in regard to the optical appearances produced by the passage of light through it when contained in bodies submitted to microscopic exanination; and $2 n d l y$, in regard to the particles which are always, in greater or less numbers, suspended in it.

In microscopic investigations we meet with air either existing in cells or cavities in various tissues, or in the form of bubbles, confined by the liquid in which the objects are usually immersed. When surrounded and confined by liquid, it mostly assumes a splierical form, in accordance with the law of hydrostatics, that the pressure of fluids is equal in all directions; sometimes the spherical form is exchanged for that of a compressed or oblong spheroid, the result of the pressure of the glass slip covering the object. When confined in cells or cavities, it assunies the form of these. It is in general easily recognized by transmitted light, from the smooth and even darkness or shading given to its margins, whilst in the centre it appears luninous and clear. Sometimes the dark margins of air-bubbles have a pale purplish-yellow, blue or greenish tinge. By reflected light, of course no darkness is produced, but it then appears vitreous and shining, in consequence of the reflection taking place from its surface. So long as air-bubbles or confined portions of air are large, the optical appearances above described are sufficiently characteristic; although should any doubt exist as to the nature of a supposed accumulation of air, the latter must be displaced, either by pressure between two slips of glass, or by immersing the object in which it exists in some liquid and applying heat. When, however, air is confined within very minute cavities, especially when these possess definite forms, the clear centre is frequently no longer to be detected, the whole appearing perfectly black and solid; and serious errors have arisen from inattention to this circum- 
stance, as explained in the Introduction (p. xxxii).

The corpuscles of dried bone were thus formerly considered solid bodies, as their nanıe implies, and as consisting of calcareous matter, until it was found that they could be filled with a liquid. In all cases, then, where absolute certainty is required of the nature of an apparent air-bubble or accumulation of air, attempts should be made to displace the mass, either by pressure or prolonged immersion in a liquid, especially with the aid of gentle heat.

The appearance presented by air contained in tissues, is easily studied in a dry section of any liind of pith or other vegetable structure, such as elder-pith, ricepaper or cork. Cork is really heavier than water, and owes its lightness to the air it contains: see CoRk. On immersing these in water, this liquid soon enter's the lateral cells, but long digestion is required before the internal cells become filled with it and the whole of the air is displaced. Soaking in alcohol before immersion in water greatly facilitates the displacement of the air.

The determination of the actual nature, as regards chemical composition, of air confined in tissues, is a niatter of difficulty where the quantities are microscopic. The nitrogen can only be detected by its negative properties to reagents ; the presence of oxygen might be determined by moistening. a section of any structure with recently boiled distilled water, and then placing it in a cell containing a solution of protosulphate of iron, and immediately sealing the cell with varnish and allowing the action to continue for some time.

For the detection of Carbonic AcId, see that article.

There is yet a source of fallacy in the detection of air imprisoned in structures where these are of a hard resisting nature, as in mineral bodies. An illustration of this, with the method of its avoidance, is given under' Topaz.

In regard to the solid particles present in, or subsiding from the air, and forming dust, these consist principally of the spores of fungi, lichens, and algæ, pollen, the detritus of the soil, fine fragments of vegetable and animal fabrics accidentally separated and diffused during the ordinary operations of every-day life, the dried but not dead bodies of infusoria, and the ova of the lower members of the animal kingdom. The kind of bodies present in the air varies according to the locality ; thus in cities, the dust consists mostly of fragments of products of manufactures, with the spores of fungi, mixed with particles of carbon or soot, the ova of the lower animal forms being comparatively few, and belonging to a limited number of species; whilst in open places in the country, a more ready diffusion of the spores of plants and the ova of animals takes place, and the sources from which fragments of textile fabrics are derived, are less numerous.

The inorganic particles deposited from the air, consist of fine grains of sand, wafted from the soil by winds, and rarely fall otherwise than near the currents by which they are borne. They are easily recognized by their angular forms, their resistance to conpression, and their not being destroyed or decomposed by exposure to a red heat. Certainty as to their composition can only be obtained by chenical analysis. See SAND.

The animal forms deposited from the air formerly gave rise to much perplexity. It has long been known that when solutions of various organic substances, or liquids containing these matters, undergoing spontaneous decomposition, were exposed to the air, the liquids were soon found to teem with life; infusoria of various kinds, according to the nature of the decomposing matter, being discovered in them in abundance. It seemed very natural to conclude that these derived their origin from the substances undergoing decay; and it is not to be wondered at, that the fact should have given rise to the conclusion that here was evidence of the spontaneous or equivocal generation of animals.

This theory has now ceased to be generally acknowledged; and a common source of fallacious reasoning lies in overlooling the fact, that the air contains the germs of numerous animal forms, still capable of resuming their active vitality when they meet with the requisite conditions. Of this we have convincing proof. For, if the liquid containing the decomposing matters be heated to ebullition for some time in a bottle or other vessel, into the cork closing. which two bent tubes are inserted, and, after the air has been completely displaced by the vapour, the fresh air admitted be previously passed through red-hot tubes, which we have no reason to believe exerts any action upon it, animalcules cease to be met with, and the decomposition of the sub- 
stance and growth of the organisms no longer take place, even in an indefinite period. That the liquid in these cases does not experience alteration rendering it incapable of supporting the life of the animal forms introduced, is shown by subsequently admitting air which has not been heated to redness, when the animalcules appear as rapidly as in fresh liquids. During the last few years, however, these experiments have been repeated in various ways, and extremely contradictory results have been obtained, into whicls we cannot enter.

In the infusoria, which are the forms most frequently met with in infusions of decaying substances, and the increase of which takes place in a threefold manner, by subdivision, gemmation, and the formation of swarmgerms and ova, we cannot wonder that the reproductive bodies are frequently not recognizable, when we recollect that the perfect organisms themselves, in many cases, are often barely within the reach of the highest powers of our microscopes.

A list of the animalcules most commonly existing in, or conveyed by the air, will be given under the head of those liquids in which we find them living: see also the articles Infusions, Generation (spontaneous), Fermentation, and PutreFACTION.

Vegetable forms are constantly met with as deposited from the air. In them, the spores are probably alone the bodies by means of which the diffusion of the lower plants by the agency of the air is effected. Minute fungi are frequently found, like the animalcules above alluded to, in various vegetable and animal liquids undergoing fermentation and decomposition. The question of the relation of these fungi to the processes, will be found discussed under Fermentation and Putrefaction; and the various genera and species found in different kinds of liquids are treated of under the heads of these liquids. Fungi and algæ are also met with as parasites and entophytes upon and in living animals; for an account of these, see Parasites and ENTOPHYTES.

The lower forms of fungi are frequently found growing upon surfaces from which they can derive no nourishment, as upon slips of glass, window-panes, \&c. In these cases they must derive their nourishment from the atmosphere. When found in these situations, however, they soon cease to grow by subdivision of cells or gemmation, but speedily form spores. The most common ones in these situations are the sugar fungus, Penicillium glaucum and Aspergillus penicillatus, Mucors, \&c.

The method of distinguishing whether any minute particle deposited from the air is of animal or vegetable nature, is described under Tissues, Animeal and VeGETABLE.

Organic bodies derived from the air are sometimes met with in snow and hail. These are alluded to in the articles SNow and HArL.

The air has frequently been examined in regard to the presence of animal or vegetable organisms, wlich might account for the production of epidemic and infectious diseases. In none of these cases have any bodies ever been found which could in any way be interpreted as the origin of the diseases; nothing more has been met with than common infusoria and such other bodies as may at all times be found in air, from whatever source. As these experiments cannot, however, be too frequently repeated, it may be well to point out the method of making them. The best plan is to connect a glass tube, twice bent at right angles, with an aspirator; the free end of the tube should be drawn to a fine point, and just above this the tube should be blown into a bulb. The point is then immersed in a small quantity of pure water, and the water allowed to run very slowly from the aspirator. The water is then slowly drawn into the tube and the air is washed as it passes by the water in the bulb. When a large quantity of air has been washed by the water, the latter is shaken briskly and allowed to run into a clean glass for examination.

Another method consists in closing, by fusion, the end of a glass funnel, filling this with ice, and collecting the drops of water condensed from the air in a receptacle placed beneath.

Pouchet and Maddox have devised other forms of apparatus for this purpose.

The appearances presented by air as existing in cell-cavities is represented in Pl. 38. fig. $23 a$; in the delicate cavities of a hair in Pl. 22. fig. 1 ; and the lower part of the same figure represents a portion from which the air has been displaced by liquid.

Bubl. Pasteur, Compt. Rendus, 1860, Sept. 3, p. 348 (Qu.Micr.Joum.1861, p.118); Pou chet, "Atmospheric Micrography," Compt. Rend. 1859-60 (Qu. Micr. Journ. xviii. pp. 
130, 188), and Nouv. Expér. s.l. gén. spont. \&c. 1863; Maddox, Month. Micr.Journ. iii. p. 286 .

AIR-BLADDER of Fishes. See SwrmMING BLADDER.

AIR-BUBBLES. See AIr.

AIR-CELLS or sacs of animals.-These are dilatations or expansions of the airpassages; but a distinction must be made between them and the lungs, which might be regarded also as air-cells. See Luvgs.

The proper air-cells or air-sacs, as met with in birds, are membranous cavities communicating with the lungs and distributed through the chest and abdomen. These air-sacs, or prolongations of them, extend over almost all parts of the body, around the joints of the extremities, into the bones, the quills and the featliers, and even between the skin and subjacent muscles. During inspiration, the air enters all these cavities.

In insects the air-cells or sacs consist of dilatations of the tracheæ. See Trachem.

Their obvious use is either to diminish the specific gravity of the body, or to act as reservoirs of air during the impeded respiration connected with flight.

Brbl. Siebold and Stannius, Lehrb. $d$. vergleich. Anat.; Owen, Iunterian Lectures; Carpenter, Man. of Compar. Anat.; Gegenbaur, Vergl. Anat. p. 822.

AIR-PASSAGES in plants are large intercellular passages, occurring especially in the stems of Monocotyledons and in the leaves and stems of aquatic plants. Their form and arrangement are sometimes very regular and elegant, especially when they depend upon a certain regular peculiarity of shape in the cells which form the walls of the passages. Thus cross sections of the common rush are pleasing microscopic objects, exliibiting regular stellate cells, the rays of which are separated by large air-passages, giving the spongy texture to the structure. Large air-passages, communicating with the stomata, are not unfrequently lined by a cuticular layer similar to that found upon the external surface of epidermal cells. In the Nymphceacece (Water-lily Order) the large air-passages in the floating leaves and the stem have peculiarly developed star-like cells projecting freely into these cavities; these cells are filled witl a granular substance very unlike the contents of the large cells of the general parenchyma of the leaf. Their nature and office are yet unknown. The partitions separating the air-cells horizontallyin Limnocharis Plumieri and Alisma plantago form beautiful microscopic objects. The stems of the Equiseta, or Horse-tails, present a very regular arrangement of perpendicular air-passages in the thin walls of their hollow stems, seen well in cross sections. See Equisetacez.

AIR-SACS in plants.-The genus Utricularia, or Bladder-wort, takes its name from a peculiar structure of its leaves. The common species, $U$. vulgaris, L., often found swimming just below the surface of the water, in quiet streams, is provided with a curious floating apparatus, formed by modification of portions of the feathery leaves, consisting of small membranous sacs or pouches, closed by a valve. The opening of the pouch is somewhat funnel-shaped; and the mouth, as also the internal walls of the cavity, is furnished with curious microscopic glandular hairs. Certain of the cells contain a blue colouring-matter distinct in its nature from chloropliyll. The valve of the pouch appears to be capable of opening inwards only; so that while it is turgid with sap, in the vigorous periods of life, it is kept closed by the pressure of the air apparently secreted within the pouch; afterwards the tissue loses its tension and the air makes its way out, allowing water to enter, and thus putting an end to the performance of the function of the air-sac.

Bibl. Meyen, Secretions-Organe der Pfanzen, Berlin, 1837, p. 12. t. v. figs. 1-6; Göppert, Botanische Zeitung, 1847, p. 721 ; Benjamin, Bot. Zeit. 1848, 1 et seq.; Schleiden, Principles of Botany, Engl. translation, pp. $77-279$.

AIR-TUBES ofInsects.-These are horny tubes found in some insects which live in water, as the larvæ of many Diptera and some water-bugs (Nepa, Ranatra). They are placed either at the first or last abdoninal segment. See Nepa, Culfex, Insects.

AIR-V ESSELS in Insects, see TrACHE $\approx$. In plants, see Spirat Structures.

ALA'RIA, Greville.-A genus of Laminariacex (Fucoid Algæe), distinguished by their superficial fructification, arranged in definite patches on the surface of special fronds, something like the sori of Ferns. The patches consist of sporang'es resembling' the thecæ of lichens, crowded togetlier and interposed between perpendicular epidermal cells. The sporanges of $A$. esculenta are described by most authors as pyriform spores enclosed in a perispore, but they perhaps produce biciliated zoospores like those of Laminaria. See Laminaria. 
Brbl. Harvey, Brit. Marine Algre, p. 29. pl. $3 \mathrm{~A}$; Greville, Alg. Brit. p. 25.

ALBERTIA.-A genus of Rotatoria. See Albertina.

ALBERTINA.-A family of Rotatoria (Duj.).

Char. Body cylindrical, vermiform, rounded in front, with an oblique orifice, from which the ciliated organ, scarcely broader than the body, projects, terminated behind by a short conical tail. Jaws forceps-like, simple or unidentate.

This family contains only a single genus, and this a single species, $A$. vermiculus (Pl. 34. fig. 4), which lives parasitically in the intestines of worms (Lumbrici) and slug's (Limaces). Length 1-47 to 1-79".

Within the body are seen ova and foetus in various stages of development. The ciliated apparatus in front of the mouth is surmounted by a hood-like appendage.

ALBU'MEN (Chemical). - A proximate principle of animal and vegetable bodies, with which we are familiar as occurring in the white of ego. It exists in two states, uncoagulated and coagulated. At a temperature of $160^{\circ} \mathrm{F}$., provided no free allali is present, it is reduced from the former into the latter condition. Its chemical relations to other proteine compounds are not very firmly established. It is reddened by Millon's test; is insoluble in acetic acid; is rendered purple by Pettenliofer's test, but the reaction requires some time for its production. In the coagulated state it is disting nished from fibrine by the action of acetic acid, and by its insolubility under prolonged digestion at a heat of $110^{\circ} \mathrm{F}$. with solution of nitrate of potash. When heated with strong muriatic acid, it is coloured purple.

Albumen possesses no microscopic characters; when coagulated, it appears to consist of extremely tine amorphous granules. See Proteine.

BrbL. See worlis on Chemistry; Brande's Chemistry; Lehmann's Physiol. Chemie.

ALBUMEN, or PERISPERM(of seeds). -This is a technical term used in Botany to denote the cellular structure which exists in greater or less quantity in all seeds where the development of the embryo is not accompanied by the entire absorption of the nucleus of the ovule. When the embryo does so displace the nucleus, it becomes immediately invested by the seed-coats; in other cases it is found imbedded in a mass of cellular tissue ef varying structure, which is the 'albumen.' The structure of albumen corresponds to that of the cotyledons of seeds devoid of albumen, both serving the same office, namely that of reservoir of nutriment for the germinating seed. This nutriment may be laid up in different conditionsnamely, in the state of starch, oil, aleurone, or of cellulose, and in the last case in a soft and fleshy; or a hard and horny condition. Combined conditions are often met with in the same structure, as when a fleshy tissue contains starch or oil in the cavities of its cells, \&c.

Starchy, mealy or farinaceous albumen constitutes the chief part of the seeds of many plants, especially of those of the Grasstribe, and is that portion of the corn-grains whence white flour is obtained. Here the cellular tissue is composed of membranous cells densely filled with starch-grains(Pl. 37. fig. $2 a$ ). The edible portion of the cocoa-nut is the corresponding region of that seed, and affords us a good example of an oily albumen, composed of tolerably thick-walled cells filled with a viscid mucilage, in which numerous oil-globules are suspended. The stone of the Date, the nut of the Areca Palm (Pl. 38. fig. 21), are good examples of a horny albumen, the cells possessing walls of extreme thickness, traversed by pores and formed, like wood-cells, by the deposition of successive layers. In the ripe seed the structure of this horny albumen is generally much disguised, and a section exhibits the appearance of a homogeneous horny substance excavated into irregular cavities. By applying dilute sulphuric or sulpho-chromic acid, the true boundaries of the cells may generally be distinguished, and often even the lamination of the walls (Pl.38. fig. 22). The substance called Vegetable Ivory is the albumen of the seed of the Phytelephas Palm, and is an instance of an extreme degree of development of the cellulose albumen, vying with the hardest woods in the solidity of its cell-walls. A fine section of this albumen, especially if treated with acid, at once reveals the cellular structure of this dense substance (Pl.38. fig. 23). The true structure may also be detected by the help of polarized light (see Polarization). The cotyledons of many seeds are, as above stated, formed of elementary structures resembling those of albumen. We find them farinaceous, fleshy, or oily, but rarely attaining to a very great degree of solidity in the horny form. The cotyledons of beans are composed of a fleshy cellular tissue with thick; porous walls, coloured blue by 
iodine alone (amyloid), while the cavities of the cells are filled with starch-grains. The cotyledons of the almond, nut, \&c. are examples of fleshy cells containing abundance of oil-globules.

The albumen of seeds may be formed by the development of the tissue of the nucleus of the ovule, in which case it is distinguished by some botanists as the episperm; generally it is formed from the cells inside the embryo-sac, the latter expanding to displace the nucleus which becomies absorbed; such albumen is called endosperm. Some seeds, such as those of the Nymphæaceæ, Piperacer and others, have both endosper'm and episperm, $i . e$. albumen formed inside and outside the embryo-sac. The term perisperm is often (advantageously) substituted for albumen, which has quite a different signification in physiological chemistry.

The albumen of seeds is examined by means of fine sections. In the horny or bony seeds, the application of solution of potash or nitric acid is very serviceable in ascertaining the true cellular structure.

BıbL. Schleiden and Vögel, Ueber Albumen, Nova Acta, 1838, xix. p. 52 (plates).

ALCYONELLA.-A g'enus of freshwater Polyzoa (Bryozoa), belonging to the order Hippocrepia and family Plumatellidæ.

Char. Tubes branched, adherent to each other by their sides; orifices terminal; ova (statoblasts) presenting an outer ring, but free from spines.

Polypary (polypidom) encrusting; and forming a sponge-like brown or greenish mass, attached to submersed woodell posts, \&c. 3 species :-

1. A. stagnorum (fungosa), Pl. 333. fig. 3. Polypary indefinite; orifices of tubes entire, and without a furrow. Common.

2. A. Benedeni. Polypary indefinite; tubes emarginate at the orifice, and furnished with a longitudinal furrow. Rare.

3. A. Aabellum. Polypary fan-shaped; tubes prostrate, with a furrow. Rare.

BIBL. Johnston, Brit. Zooph. p. 391; Allinan, Freshwater Polyzoa (Ray Society), p. 86; Nitsclee, Müll. Archiv, 1868.

ALCYONIDIAD A (Halcyonellea, Ehr., Johnston).- A family of marine Polyzoa (Bryozoa), of the order Infundibulata, and suborder Cyclostomata.

Char. Polypary sponge-like, fleshy, of irregular form; cells irregularly arranged, immersed, with a contractile orifice; no external ovarian capsules. Genera:-
1. Alcyonidium, Lamx. Erect; lobed or simple; cells pentagonal.

2. Cycloum, Hass. Encrusting, covered with imperforate papillæ; eggs in circular clusters.

3. Sarcochitum,Hass. Encrusting, covered with perforate prominences in which the cells are immersed; eggs scattered singly throughout the polypidom.

Bibl. See the Genera.

ALCYONIDIUM, Lamx. - A genus of Infundibulate Polyzon (Bryozoa), of the suborder Ctenostomata, and family Alcyonidiadæ.

Char. Erect, lobed, or simple; cells immersed, pentagonal.

Three British species; they occur attached to marine objects by a narrow base.

1. A. gelatinosum. Lobed, lobes subcylindrical, surface smooth; attached by a narrow base. Deep water.

2. A. hirsutum. Lobed, compressed, surface papillar from partial protrusion of the polype-cells. Common.

3. A. parasiticum. Encrusting, earthy, surface porous.

BıbL. Johnston, Brit. Zooph. p. 358; Gosse, Mar. Zool. ii.; Hassall, Ann. Nat. Hist. vii. p. 370 ; Reid, ibid. xvi. p. 393.

ALCYO'NIUM. - A genus of marine Polypes or Zoophytes, belonging to the order Anthozoa, and family Alcyonidæ.

Char. Polype-mass lobed or encrusting, spongy, containing scattered calcareous spicula. The skin coriaceous, marked with stellate pores; interior gelatinous, netted with tubular fibres and perforated with longitudinal canals terminating in the polypecells, which are subcutaneous and scattered. Polypes exsertile. Two species:-

1. A. digitatum (spicula, Pl. 33. fig. 28), Commonly called 'dead man's toes or hands,' and cows'-paps. Form of polypidom variable, greyish-white or orange-coloured, skin sonewhat wrinkled, studded over with stellate pores, even with the surface.

Very common, so that on many parts of the coast scarce a shell or stone can be dredged from the deep that does not serve as a support to one or more specimens.

2. A.glomeratum. Colour deep red; rare. Bibl. Johnston, Brit. Zoophytes, p. 174 ; Gosse, Mar. Zool.; Gray, Am. Nat. Hist. 1869, v. p. 117.

ALDERIA.-A name proposed by Pritchard to designate a new and doubtful genus of aninials discovered by Alder.

The body of one species (Pl. 40. fig. 14) 
ALECTO.

consisted of a rase- or cup-form, expanded at the top and furnished with numerous pointed tentacles, abruptly thickened towards the base and forming more than one row. Body attached to a Sertularia by a tolerably stout stem.

A second species was rather smaller, the body of an ovate form with a very slender and shortish stem ; the tentacles were capitate, not so numerous as in the first species, and placed in a single row round a narrow disk.

This was also found on a Sertularia.

A third (Pl.40. fig. 15) was found in fresh water. Body pear-shaped, or rather bellshaped, with a distinct rim, and a single row of delicate capitate retractile tentacles; the stem was long and slender. Alder remarks that they come nearest to the genus Acineta of Ehrenberg. Similar organismis have been observed by Str. Wright; and they greatly resemble some of Claparède and Lachmann's Acinete.

Bibl. Trans. of Tymeside Naturalists' Field Club, i. p. $365 ;$ Ann. Nat. Hist. vii. p. 426; Pritchard's Inf. Anim. p. 562.

ALECTO, Lamx.-A genus of marine Polyzoa, of the suborder Cyclostomata and family Tubuliporidæ.

The three British species are found upon old shells and stones from deep water.

1. A. granulata. Cells in one or occasionally two rows, their walls granular.

2. A. major. Cells in more than one or two rows, their walls smooth.

3. A. dilatans. Branches of polypary dilated at the ends; cells in several rows, their walls granular.

Bibl. Jolinston, Brit. Zooph. p. 280; Busk, Cat. of Mar. Polyz. (Brit. Mus.).

ALECTORIA, Acharius.-A genus of ParmeliaceousLichens,including two British species, $A$. jubata and $A$. sarmentosa, the fructification of which is rarely met witl.

ALEU'RONE (Gluten-flour).- This orgrnized cell-substance, like starch, is very generally diffused through the vegetable kingdom, occurring in most sceds. It exists in large quantity in castor-oil and lupineseeds, in muts, almonds, cocoa, and coffeebeans. It was long overlooked, on account of its solubility in water. It consists of minute granules, of a spherical form, often pitted on the surface, either solid or hollow, and covered by a membrane. These are insoluble in ether, alcohol, and fixed oils; but soluble in water, dilute acids, and alkalies. It is coloured deep yellow by iodine, and intense red bycarmine-solution. Nitrate of mercury renders the interior brick-red, but does not colour the wall. Each granule consists principally of albuminous matter, but also contains gum and sugar. In many of the grains, as in those of castor-oil seeds, large crystals are met with. Aleurone is usually colourless, sometimes green, as in pistachio-nuts, yellow in Ailanthus-seeds, or blue. It is most easily examined in a thin section of an almond immersed in oil.

The nutritive properties of many seeds (nuts, almonds, \&c.) depend to a considerable extent upon the presence of aleurone.

Brbu. Hartig, Bot. Zeit. 1857; Wiesner, Techn. Mikrosk. p. 74, 1867.

ALGAE, Sea-weeds \&.c.-This class of the Thallophytes includes the Sea-weedsand the multifarious green vegetable forms of simple cellular structure met with in all streams, ditches, ponds, or even the smallest accumulations of fresh water standing for any length of time in the open air, and commonly on walls or the ground in all permanently damp situations. The great variety of conditions of organization, all variations as it were on the theme of the simple vegetable cell, produced by change of form, number, and arrangement of this simple element, renders the Algæ peculiarly interesting as objects of microscopical research, even in regard to morphological conditions alone.

This simple condition of the structures is here, as in other cases, accompanied by a delegation of the physiological functions most completely and fully to the individual cells; that is to say, the miarked difference of purpose seen in the leaves, stamens, seeds, \&c. of the flowering plants is absent here, and the structures carrying on the operations of nutrition and those of reproduction are so commingled, conjoined, and, in some cases, identified, that a knowledge of the microscopic anatomy is indispensable even to the roughest conception of the natural history of these plants. Added to this, we find these plants of such simple structure that we can see through and through them while living. in a natural condition, and by means of the microscope penetrate to mysteries of organization, either altogether inaccessible, or only to be attained by disturbing and destructive dissection, in the higher forms of vegetation.

This Class comprehends a vast variety of plants, exhibiting a wonderful multiplicity of forms, colours, sizes and degrees of complexity of structure; but the subdivision of them into three groups, characterized by 
striking external characters, which are adopted in the classifications of some of the leading Algologists, facilitates the cursoly consideration to which we are confined here. These three Orders are the Red-spored Algce (Rhodospore ar Floridem), the Dar spored Algce (Melanosponese or FuCOIDE $\approx$ ), and the Green-spored Alge (ChloROSPOREAOr CONFER ROIDEAE), the first two consisting almost exclusively of Sea-treeds, the last of marine and more especially (according to our present knowledge) of freshwater plants, the majority of which are microscopic when viewed singly.

The Algæ are differently distributed by Thuret, whose researches on their fructification have thrown so much light upon this class. His views are referred to under the Orders.

Order 1. Rhodosporeze or Floridez. Almost all marine plants, with a leaf-like or filamentous rose-red or purple, rarely brownred or greenish red, thallus. Fructification appearing in three forms:-1. spores, contained in external or immersed definite masses, mostly enclosed in conceptacles (ceramidia, coccidia, favellidia, \&.c.); 2. tetraspores, red or purple, either external or immersed in the frond, rarely contained in proper conceptacles (stichidlia), each consisting of a transparent membranous sac containing, when ripe, four spores; 3. contheridia, pellucid sacs filled with yellow motionless spherical corpuscles (ciliated, Nägeli), collected in masses in situations corresponding to the spore-fruits. According to Bornet and Thuret, the fertilization is effected through the agency of a style-like filiform process or trichogyne, to which the spermatozoids adhere. The trichogyne is either only the prolongation of the cell in which the spores are produced; or, more generally, it is supported upon little cells, which take no direct partin the formation of the spores.

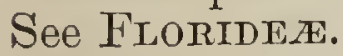

Order 2. Melanospore ar Fucordez. Marine plants with a leaf-like, shrubby, cord-like or filamentous thallus, of olivegreen or brown colour. Fructification very varied:-1. in Fucaceæ consisting of monocious or diøecious conceptacles containing sporanges and antheridia, the spores being fertilized byspermatozoids after the discharge of both from the parent; 2 . in Laminariacer and allied orders consisting of definite or indefinite collections of clavate or filiform sporanges, producing zoospores which germinate directly; 3 . in Cutleriaceæ of similar sporanges producing zoospores, togetler with antheridia, like those of Fucaceæ; 4. in Dictyotaceæ presenting three forms resembling those of Floridex, viz. collections of tetraspores, of sporanges containing simple spores, and of antheridia. See FucoIdex.

Order 3. Chlorosporez or ConfervoIDE . Plants growing in sea or fresh water, or on damp surfaces, with a filamentous, or more rarely a leaf-like, pulverulent or gelatinous thallus; the last two forms essentially microscopic, consisting frequently of definitely arranged groups of distinct cells, either of ordinary structure or with theirmembranesilicified(Diatomaceæ). Fructification varied in its details, but essentially reducible to three forms:-1. resting spores produced from the cell-contents after fertilization, either by ConJUGATron or impregmation by (2.) spermatozoids produced from the contents of other cells; 3. zoospores, 2-, 4-, or multi-ciliated active gonidia, discharged from the vegetative cells without impregnation and germinating directly. The simple vegetative increase of the Unicellular forms is a process essentially analogous to the cell-division of the filamentous forms, but results necessarily in multiplication of the species. The Volvociner, now included among the Confervoid Algre, are remarkable for their passing the vegetative stage of existence in the form of ciliated zoospores, mostly collected within a gelatinous common envelope into a definitely arranged family. See Confervoidex.

Excluded families of Algæ :-

CRyptococce.e, Kg., containing the genera Cryptococcus, Kg., Ulvina, Kg., and Spherotilus, Kg.

LePtonпte $A$, Kg., containing the genera Hygrocrocis, Ag., Sirocrocis, $\mathrm{K}_{\mathrm{g} .}$, Leptomitus, Ag., Arthromitus, Leidy, Cladophytum, Leidy, Mycothamnion, Kg., Erebonema, Römer, Chamcenema, Kg., Nematococcus, Kg., Chioniphe, Thienemann, Moulinea, Ch. Robin, Enterobryus, Leidy, Eccrina, Leidy.

PHeonemese, containing the genera Stereonema, Kg., Phïonema, Kg., Phaosiphonia, Kg.

All these are byssoid or mucoid products occurring in organic liquids undergoing fermentation, vinous, acetous, or putrefactive, or in solutions of mineral salts, which are likewise decomposed by them. They are probably mycelia of various Fungi and not independent organisms.

Brbl. Harvey, Man. of British Alga, 2nd ed. 1849; Phycologia Britannica; C. 
Agardh, Syst. Algarum; J. Agardl, Species, Genera et Ordines Algarum; Kützing, Phycol. generalis; Species Algarum; Tabula Phycologica; Phycol. Germanica; Lyngbye, Hydrophytologia Danica; Greville, Alge Brit. ; Berkeley, Cryptogamic Botany, p. 84; Henfrey, Elem. Bot. (Masters), p. 432 ; Thuret, Amn. d. Sc. Nat. 1855 ; Rabenhorst, Beit. z. näher. Kenntniss d. Algen, 1865 ; id. Flora Europ. Algarum, 1865; Bornet and Thuret, Ann. d. Sc. Nat. 1867, vii. p. 166 (Ann. Nat. Hist. 1867, xix. p. 35).

ALICULARIA, Corda.-A genus of leafy Liverworts (see Jungermannie $A$ ), containing one British species, common on hedge-banlss.

A. scalaris $=$ Jungermannia scalaris, Schrad., J. lanceolata, Eng. Bot. (fig. 7).

Jungerm. compressa, Hook., which has stipules only on the innovations, is included in this genus by Fries and others.

Bibi. Hooker, British Jungermannice, pl. 61; Sowerby, gone (magni-
Enql. Botamy, pl. 605 .

ALKALOIDS.-The utility of the microscope in distinguishing the more common alkaloids from each other, has been shown in an able paper by Dr. Anderson. The characters consist in the crystalline form of the alkaloids, and in that of their sulphocyanides.

The method consisted in dissolving the alkaloids in dilute hydrochloric acid, and mixing the dilute solution, on a glass plate, with solution of ammonia of moderate strength if the alkaloid itself is to be examined, or with a strong solution of the sulphocyanide of potassium if the sulphocyanide is required, and at once placing it under the microscope. The only precaution requisite is to avoid having the solution too concentrated, as the crystals are then less well-defined than if a dilute solution is employed.

The power employed should be 250 diameters; for if a very high power is used, the form of the crystals is not so readily distinguished.

Atropine is precipitated in the amorphous state by ammonia, and not at all by the sulphocyanide of potassium.

Brucia. A salt of brucia in a sufficiently dilute state, mixed with ammonia, does not give an immediate precipitate; but in the course of a very short time, irregular star- like groups of pointed crystals are observed, as in Pl. 7. fig. $1 a$. Sulphocyanide of potassium produces a precipitate in tufts of extremely thin and feathery crystals, which either radiate from a centre, or present a sheaf-like appearance. The latter form, however, is much better marked in the crystals deposited after some hours from a dilute solution, which are still microscopic, although somewhat larger than those represented in the figure (Pl. 7, fig. 1 b).

Cinchonine is obtained by precipitation with ammonia in the form of minute graniular masses, made up of more or less distinctly acicular crystals, radiating from a centre. It is, however, somewhat difficult to obtain them well-marked, and they not unfrequently appear as a confused mass of granules, in which the radiated structure is very imperfectly seen. They form best when the solutions are rapidly mixed (Pl. 7. fig. 2). With sulphocyanide of potassium, cinchonine gives a precipitate consisting of six-sided plates, together with a variety of irregular crystalline masses, and a few rectangular plates (Pl. 7. fig. 3). When formed by mixing' in a test-tube with agitation, and allowing it to stand for some time, the crystals are still microscopic, but much more definite, and sometimes consist almost entirely of isolated six-sided tables, of great regularity. The precipitate dissolves readily in hot water, and is deposited as the solution cools, in irregular plates.

Narcotine is precipitated by ammonia in branched groups of pointed crystals (Pl. 7. fig. 4). In concentrated solutions a precipitate is thrown down by sulphocyanide of potassium, which dissolves readily in hot water, and is again deposited on cooling. Under the microscope it is perfectly amolphous.

Strychine. The hydrochlorate, treated with ammonia, gives an immediate precipitate, consisting of minute prismatic crystals, all nearly of the same size and very well defined. Most are isolated, but some cross each other at an angle of about $60^{\circ}$. When lying in one position, they exhibit more or less an appearance of a Saint Andrew's cross, with a peculiar arrangement of their terminal facets (Pl. 7. fig. 5). The sulphocyanide consists of flattened needles, sometimes single, but generally in irregular groups, as in Pl. 7. fig. 6. They are either terminated by a blunt acumination or are truncated. Those precipitated on the large scale present the latter forms. 
Morphia. Ammonia does not produce an immediate precipitate in solutions of morphia; but in the course of a longer or shorter period, according to the degree of dilution, crystals form, which gradually increase in size, and possess the form represented in Pl. 7. fig. 7. Salts of morphia are not precipitated by sulphocyanide of potassium, unless the solution is highly concentrated.

Quinine. Its solution gives with ammonia a perfectly amorphous precipitate; with sulphocyanide of potassium it gives small irregular groups of acicular crystals, resembling those produced by strychnia, but longer and more irregular (Pl. 7. fig. 8). When the precipitate is produced in a testtube, and with a concentrated solution, it falls immediately as a white powder composed of extremely minute needles; but when the solution is dilute, it is deposited after the lapse of twenty-four hours, in crystals from 1-4th to 1-3rd of an inch in length. See Quinine and Crystals.

Birl. Anderson (T.), Edinb. Month. Journ. viii. p. 570.

ALLAN"TOIN. - A crystalline organic substance found in the liquid of the allantois and in the renal secretion of the calf. As artificially prepared, it is one of the products of oxidation of uric acid.

Its crystals form transparent colourless needles and four-sided prisms, with mostly dihedral unequal summits, Pl. 6. fig. 20. They are not very soluble in either cold or boiling water, are more soluble in alcohol, but not at all in ether.

Brbl. See Chemistry.

ALLANTOIS.-An oblong or pyriform sac developed during a very early period of embryonic life from near the end of the intestine. Its function is that of a temporary respiratory organ. The capillaries in the allantois of the chick are distributed closely like those of the lumgs of the Batrachia.

Brbc. Wagner, Physiology, translated by Willis; Müller, by Baly; Carpenter, IIum. Plyss. p. 878.

ALLOMORPHINA, Reuss. - One of Reuss's "Cryptostegian" genera of perforate Foraminifera. It has the appearance of an irregular Miliola; but he describes the shell as porous. It is subtriangular, with the chambers in a triple spire, and overlapping so nuch that only the last three chamber's are visible. The aperture is a transverse slit on the inner border of the last chamber. Fossil in the Upper Chalk and Tertiary of Germany.
Bibl. Reuss, Denks. Alaad. Wien, i. 352; Sitz. Akad. Wien, xliv. 372.

ALLOSORUS, Bernh.-A genus of Adiantere (Polypodioid Ferus). A. (Cryptogramma) crispus is a native of Britain.

ALONA. - A genus of Entomostraca, belonging to the order Cladocera and family Lynceidæ.

The three British species may be thus distinguished :-

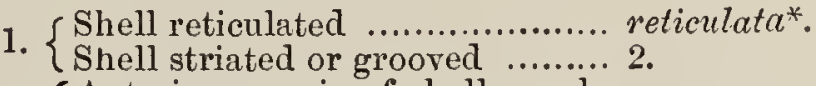
2. $\left\{\begin{array}{l}\text { Anterior margin of shell nearly } \\ \text { straight, shell brown ............ quadrangularis } \dagger \text {. } \\ \text { Anterior margin of shell convex, } \\ \text { shell colourless.................... ovata. }\end{array}\right.$

$$
\text { * Pl. 14. fig. 4. † Pl. 14. Gg. } 5 .
$$

Bms. Baird, British Entomostraca, p. 131 et seq. ; pl. 16.

ALSOPHILA, R. Brown.-A genus of Cyatherous Ferns. Exotic (fig. 8). Almost all the Alsophila are tree-ferns. Sections of their petioles exhibit fine scalariform ducts, the slits between the fibres forming many perpendicular rows.

ALTERNARIA, Nees. - A genus of Torulacei (Coniomycetous Fungi). Microsenpic filamentous Fungi, remarkable for their flask-shaped, cellular spores, produced in chains which ultimately break up into the single links (fig: 9).

A. tenuis grows parasitically upon other tilamentous Fungi, and on decaying gourds; and is common about Berlin, Prague, and other places. Corda made the ripe spores germinate on $\mathrm{Cla}$ dosporium herbarum kept moist. They usually first protruded a filament from the neck, or attenuated projection, and afterwards others from the cells at the sides and opposite end of the spore. Alternaria These filan ents became branched. Fenuis.

The Messrs. Tulasne have spore-bearshown that Alternaric tenuis is ingthreads merely a state of the common magnified). Sphceria herbarum.

BisL. Corda, Icones Fung. iii. p. 5, pl. 1. fig. 16; Prachtfl. europäisch. Schimmelbild. p. 13; Tulasne, Fungorum C'arpologia.

Fig. 9.

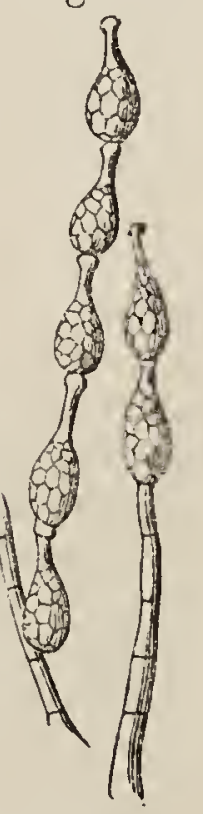$$
\text { . }
$$ 


\section{ALTERNATION OF Generations.} See Generations.

ALTEU'THA, Baird.-A genus of Entomostraca, of the order Copepoda, and family Cyclopidx.

One species, $A$. depressa (Pl. 14. fig. 3). Eye red. Found in Berwick Bay, but not common.

Brbl. Baird, Aun. Nat. Hist. xvii. p. 416; and Brit. Entomostr. p. 216.

Al'IICA. See Haltica.

ALUCTTA.-A genus of Lepidopterous insects, of the family Alucitidæ.

The species are remarkable from having the wing's divided into six lobes or rays which are fringed with long narrow scales resembling hairs, giving them a beautiful feathery appearance. They are not uncommon in gardens, and sometimes enter outhouses.

The species of Pterophorus exhibit the same structure, excepting that the anterior wings have two, and the posterior three lobes.

BIBL. See Insects (Wings).

ALUM.-This well-known substance consists chemically of potash and alumina, with sulphuric acid and water. Its crystals belong to the regular cubic or tesseral system, and usually assume the octahedral form. When dissolved in boiling water with slaked lime, it crystallizes in cubes. The term alum has recently been extended to those compounds in which the potash is replaced by other bases; thus we have soda-alum, chromealum, \&c. The crystals exert no influence upon polarized light. Common alum possesses but little niicroscopic interest. Its solution is used in some of the preservative liquids.

ALVEOLINA,D'Orb.-A genus of Foraminifera imperforata, of the family Miliolida (Carpenter), nearly allied to Orbiculina, but elongated in the direction of the axis ; $\mathrm{Or}$ biculina being greatly compressed in this direction. Alveolina rotella (1'Orb., sp.), however, is nautiloid; $A l$. melo, var. a, Ficht. and Moll, is oblately spheroidal; var. $\beta$, prolately spheroidal; $A l$. ovoidea, D'Orb., elongate-oval; Al. sabulosa, Montft., fusiform; and Al. elongata, D'Orb., is subcylindrical.

A. fusiformis (pl. 18. fig. 15) ; A. rotella (pl. 18. fig. 16).

Bris. Carpenter, Phil. Trans. 1856, p. 552 ; Introd. Foram. p. 99; Parker and Jones, Ann. Nat. Hist. ser. 3. viii. p. 161.

ALYSCUM, Duj.-A genus of Infusoria, of the family Enchelia, Duj.
Al. saltans (Pl. 23. fig. 8). Colourless, with faint longitudinal furrows; movement abruptly jerking; length 1-1260 to 1-1000".

Found in infusion of hay, and river-water, which have been kept.

Dujardin remarks that it differs from Enchelys nodulosa, Duj. (Pantotrichum Enchelys, Ehr.), only in the presence of the retractile cilia.

Brbl. Dujardin, Infus. p. 391.

ALYSSUM, Linn.-A genus of Cruciferæ (Flowering Plants), possessing elegant stellate hairs. See HAIns of plants.

AMIER E'CIUM, or AMAROU'CIUM, M.-Edw.-A genus of Mollusca, of the order Tunicata, and family Botryllidx.

Four British species :-proliferum (P1.43. fig. 10), Nordmanni, Argus, and albicans.

Bibl. M.-Edwards, Mém. sur les Ascid. Comp.; Forbes and Hanley, Brit. Mollusca, i. 15: Gosse, Mar. Zool. ii. 33.

AMATHIA, Lamx. See Serialaria.

AMBER.-This substance, found as a mineral, but strongly resembling in appearance various gum-resins, is the fossil resin of one or more Coniferous trees belonging to a vegetation now extinct. It is found in drops, lamellæ, and stick-shaped pieces, the form and condition depending probably on the mode and situation of its exudation from the trees. In many instances the fragments of antber contain well-preserved remains of the animals and plants which lived at the period of its formation, these having been enclosed by the fluid resin as it escaped from the tree, in a manner which may be exactly compared with our mode of preserving microscopic objects in Canada balsam. Numerousinsects, Arachnida, and other animals, with leaves, twig's, fruits, even flowers of plants, have been described and referred satisfactorily to their systematic position; and the aid of the microscope has been largely called in for this purpose, since the elementary structures are in many cases perfectly preserved. The tissue of fragments of Coniferous wood, the stomates of leaves, and glandular and other hairs have been recognized; and besides the larger Cryptogams, Mosses, Jungermannix, \&c., peculiar microscopie Fungi and Diatomaces have been preserved in a perfectly distinct condition.

The structure of the wood of the Amberfir, Pinites succinifer, Göpp., approaches closely that of our Pinus Abies and P. Picea, differing scarcely in any respect but in the smaller number of the bordered pores, which are of slightly different form. 


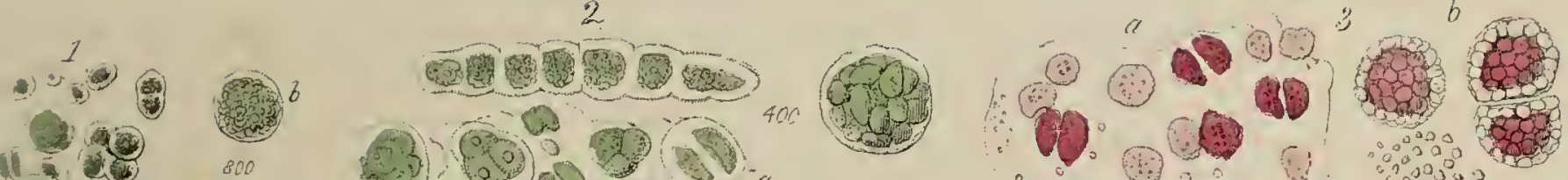

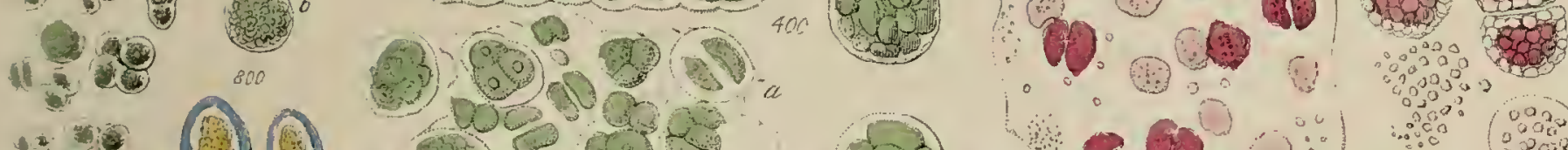

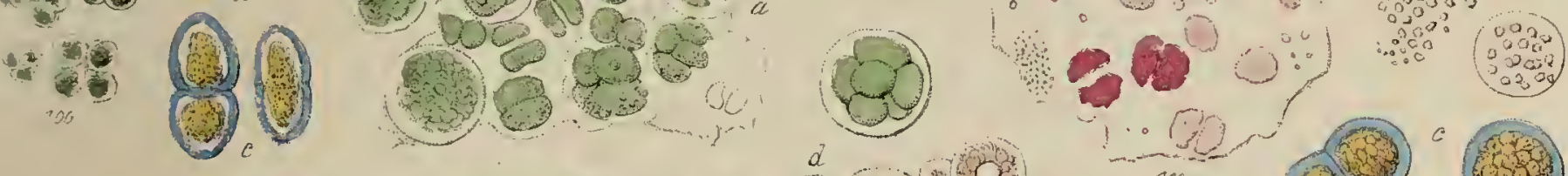

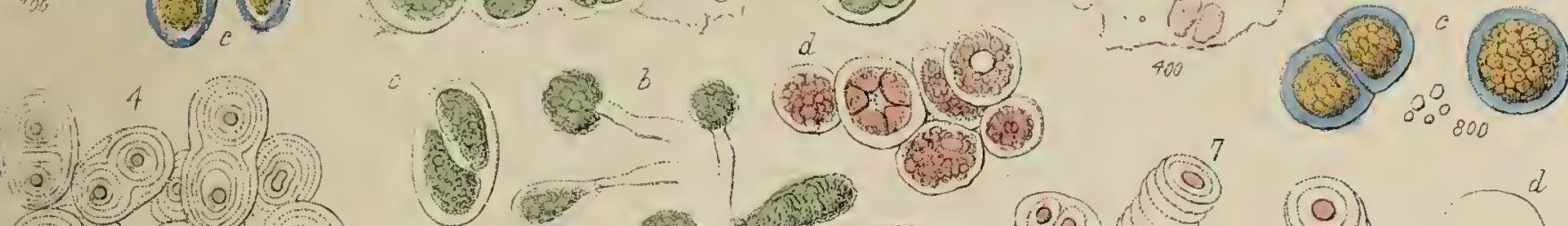

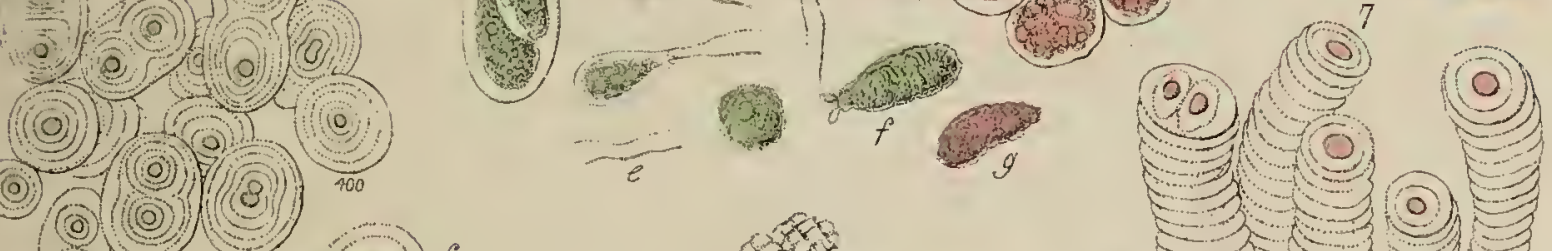

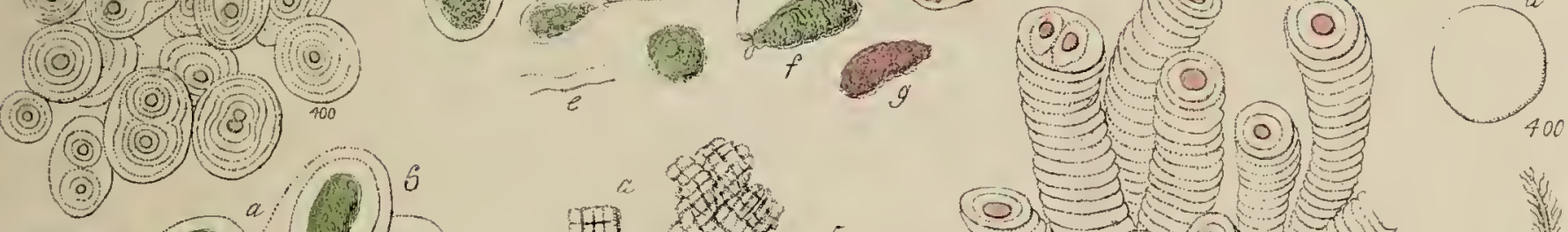

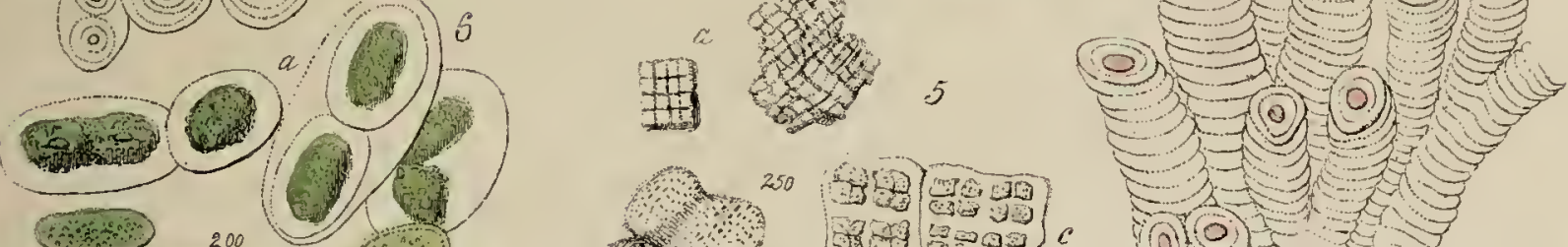
$\int c 0$ (3) 3 (1)

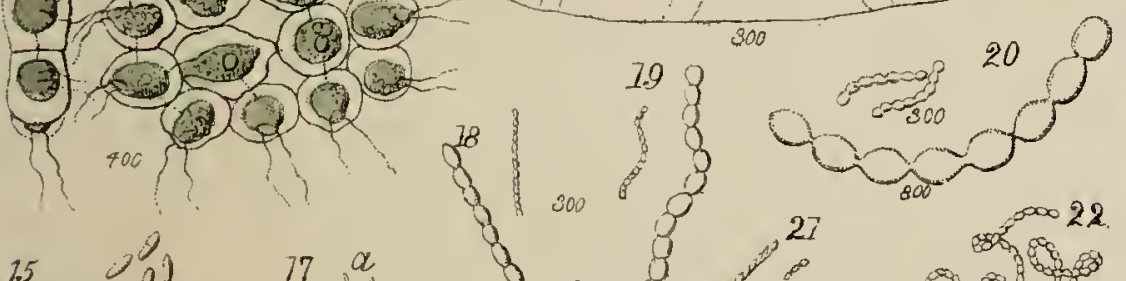
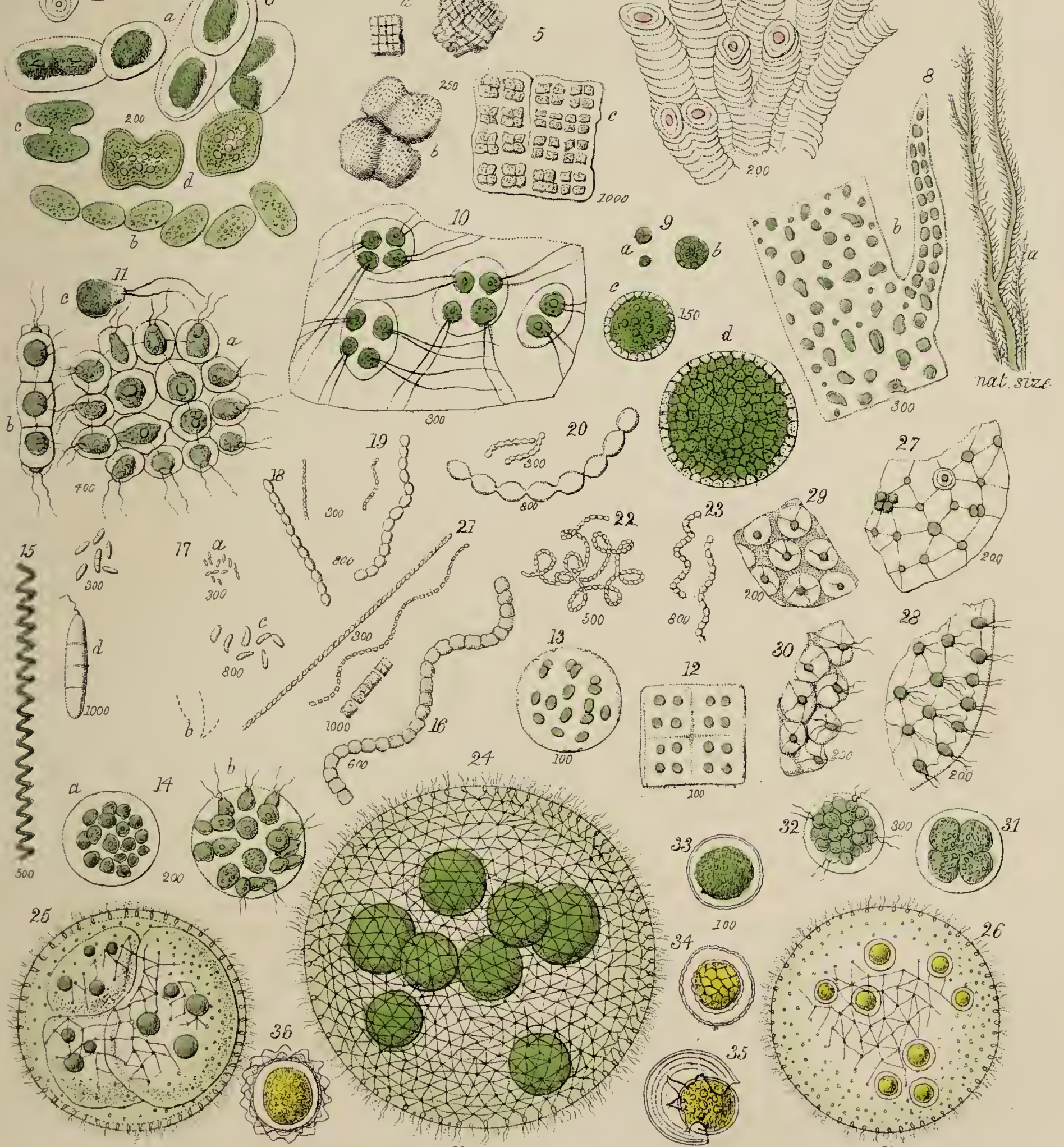


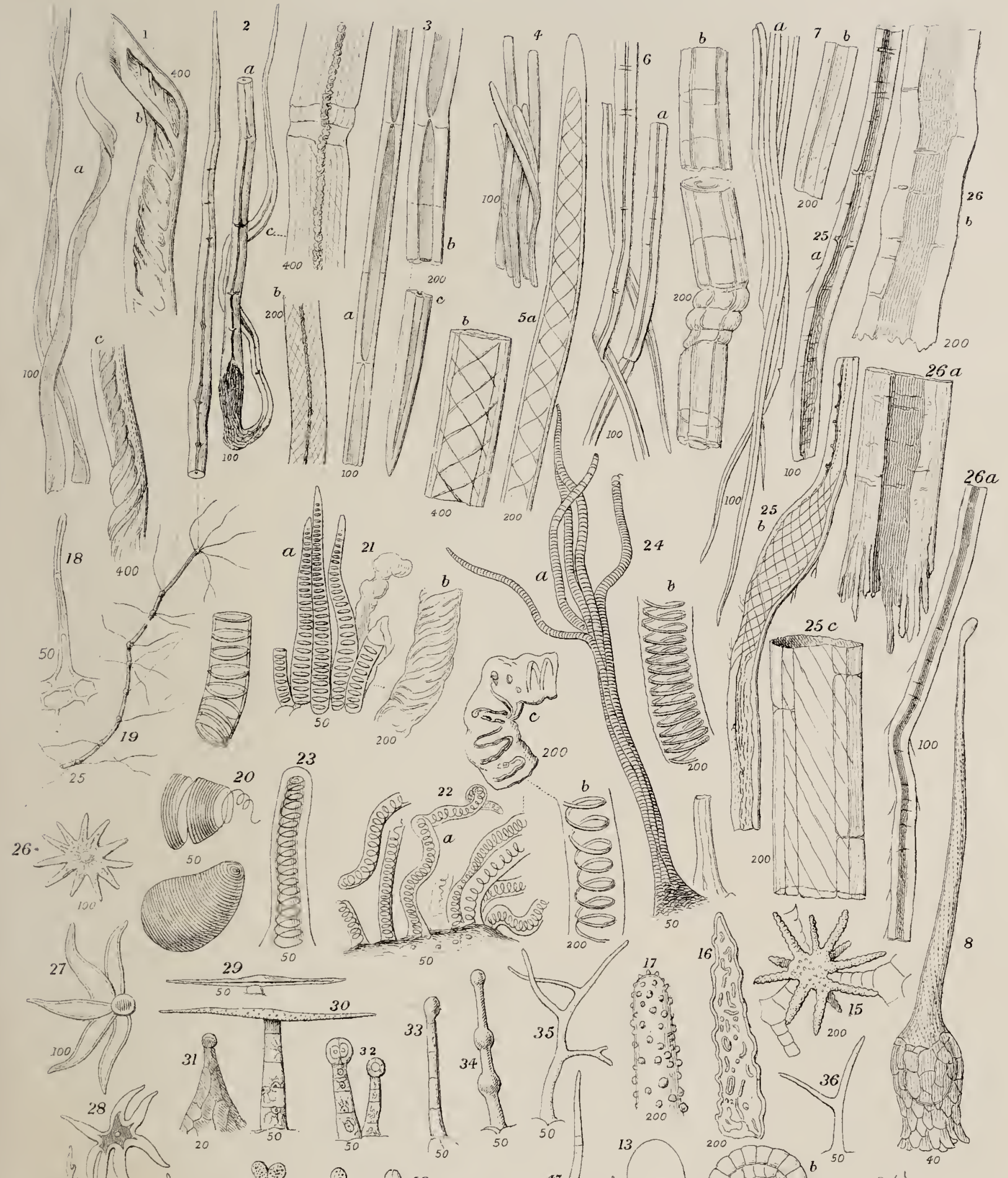

STARCH.
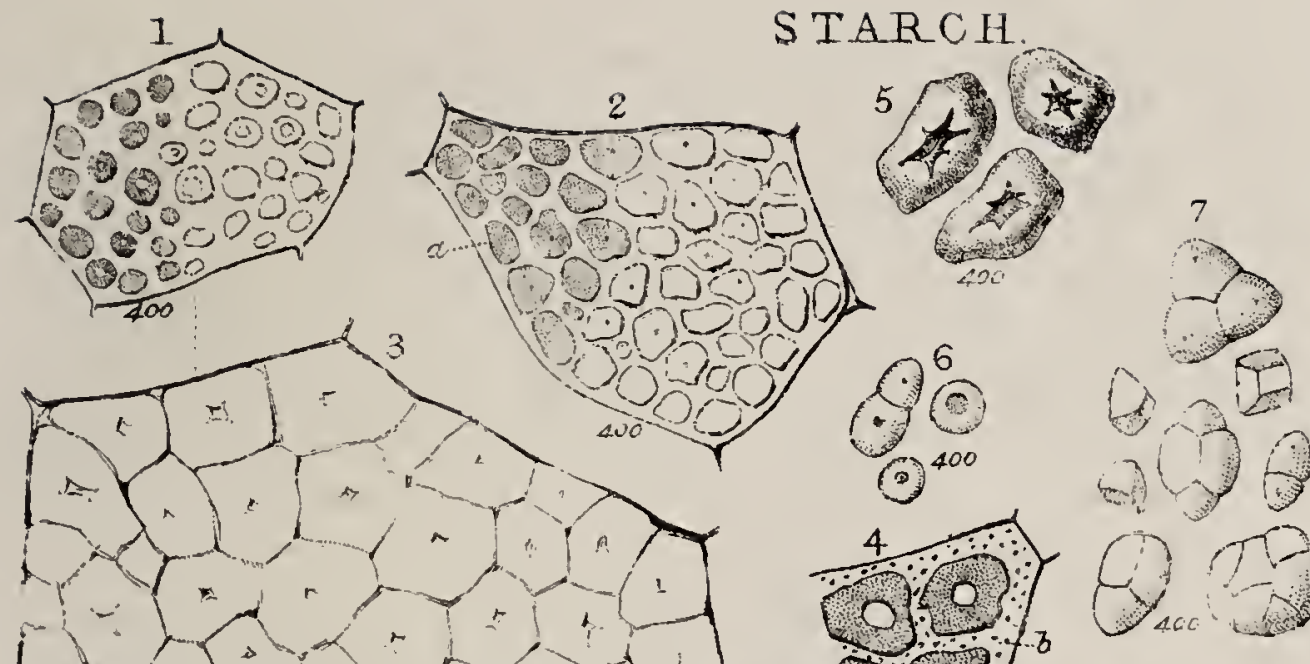

28
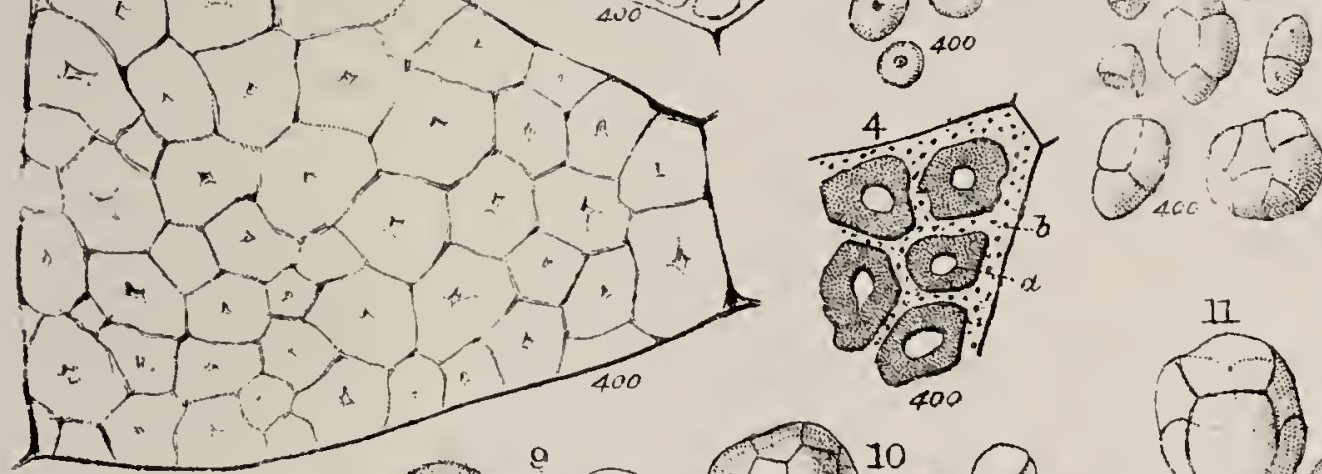

$(2)_{46}$

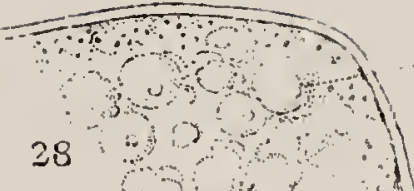

is i7

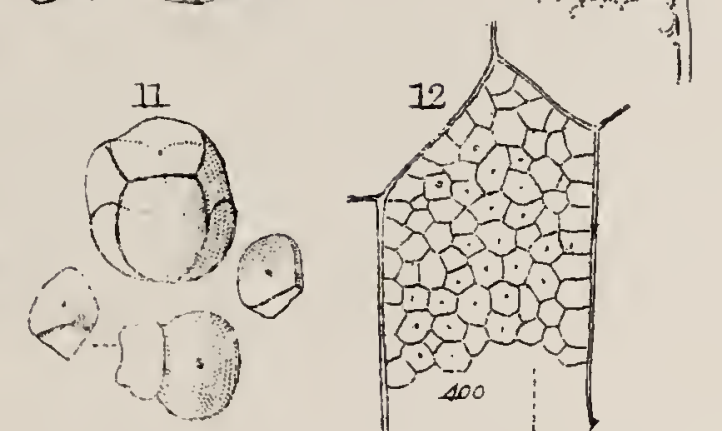

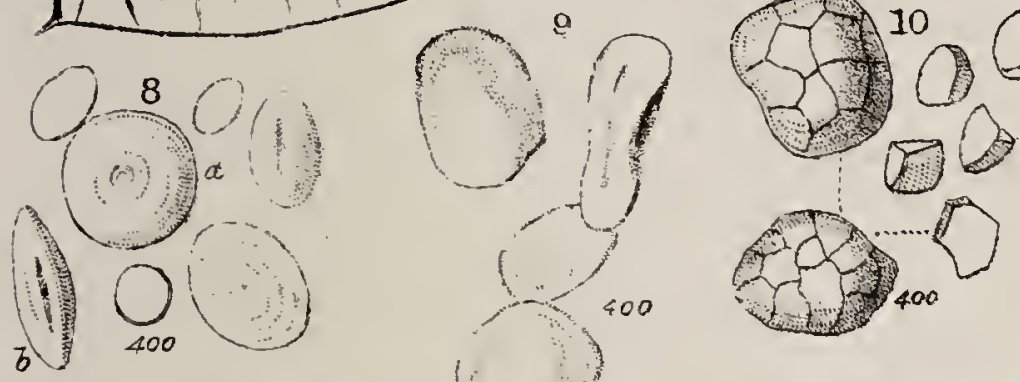
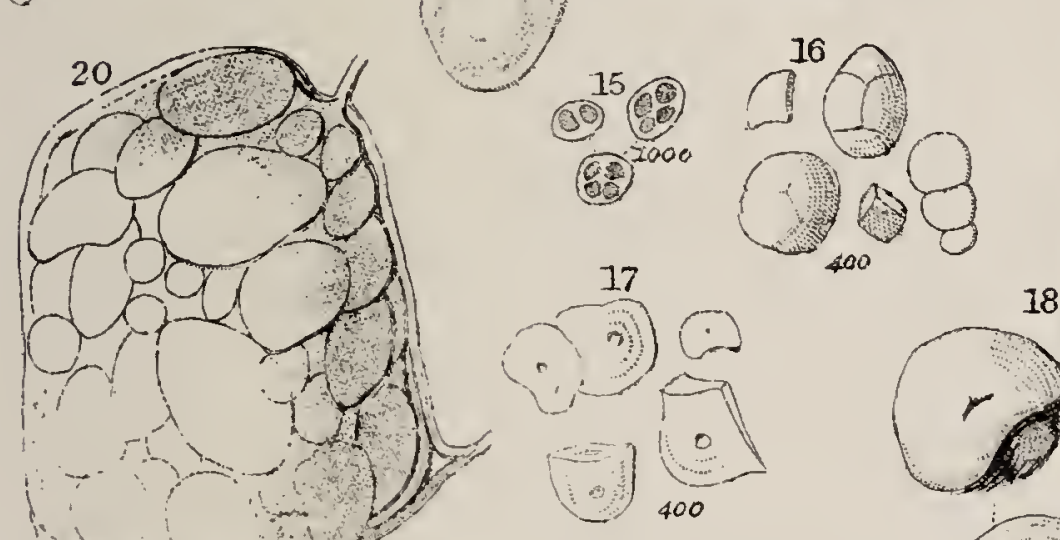

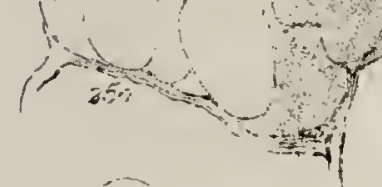
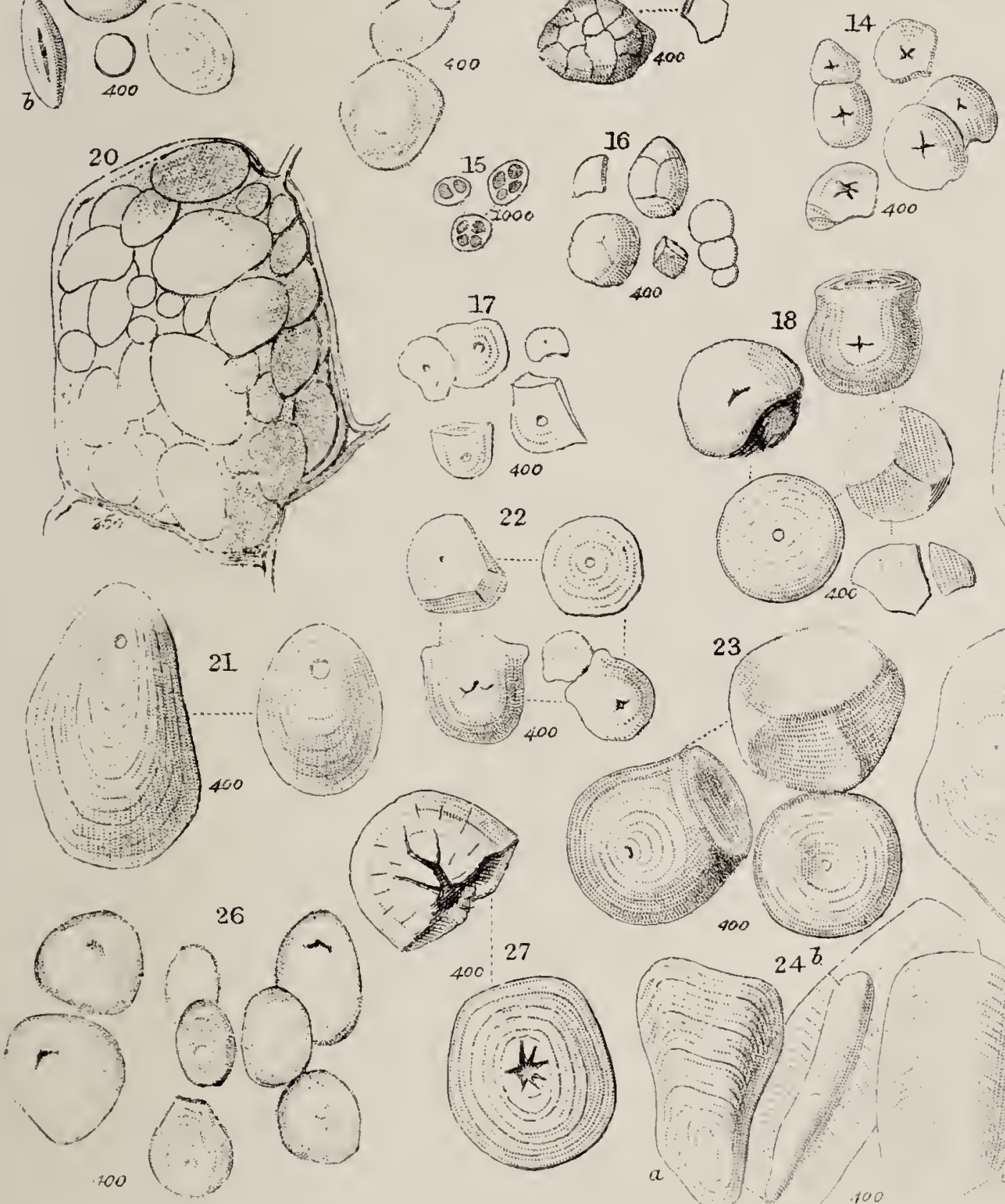

London: John Van Voorst, 1871

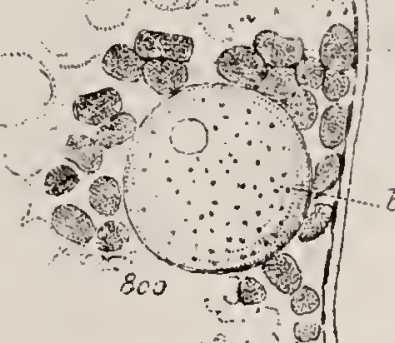



VEGETABLE TISSUES.

P1.39.
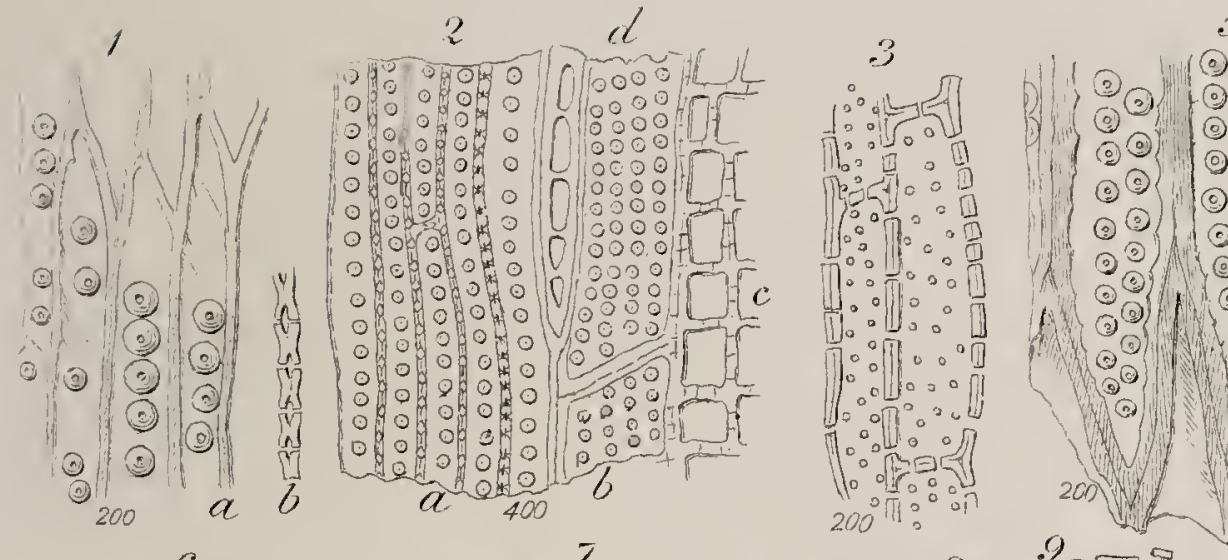

\section{5}

4
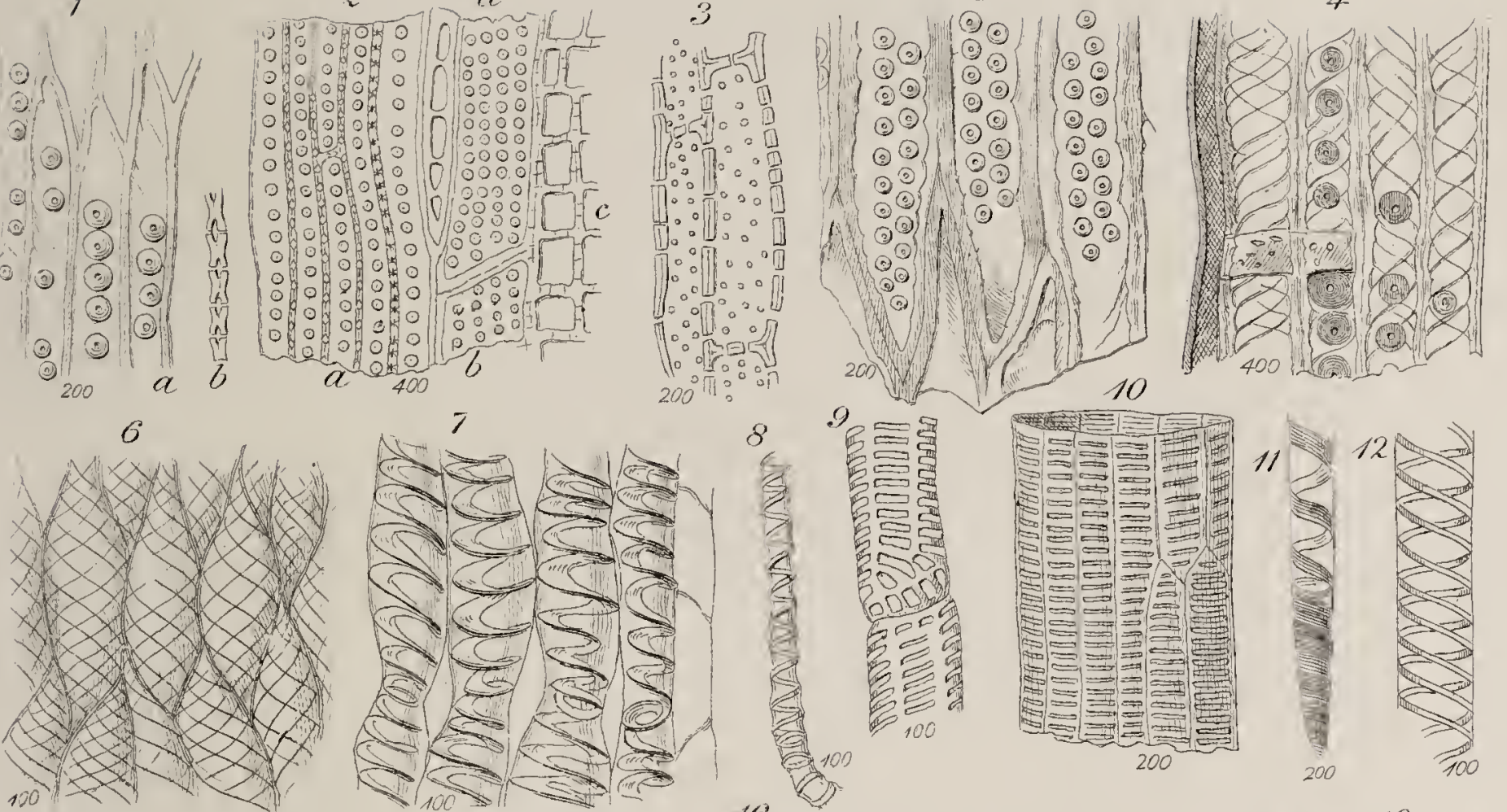

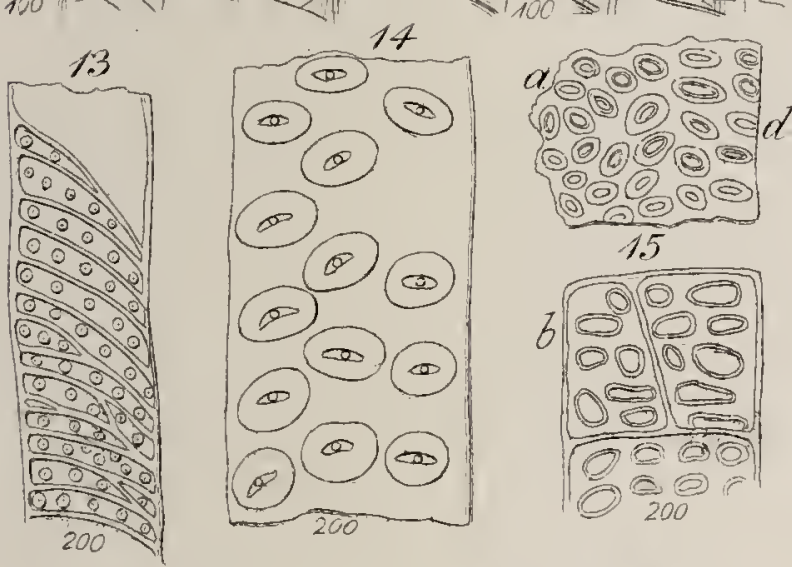
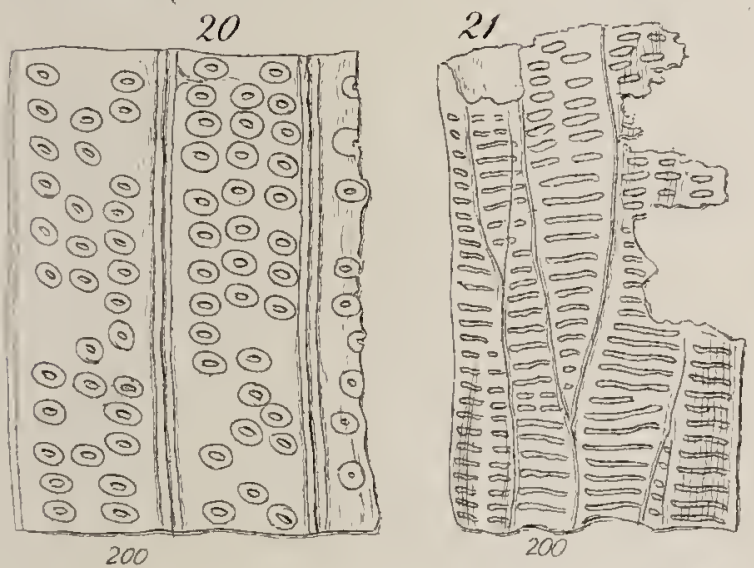

16

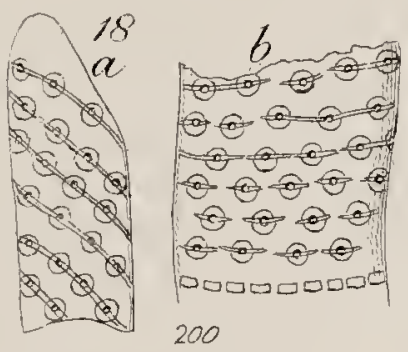

19

की के का
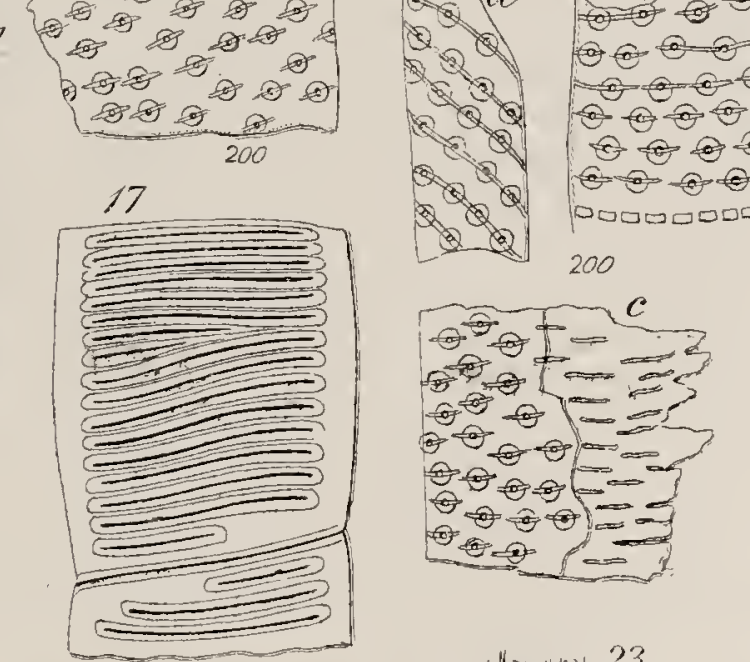

${ }^{a}$ ㄴ.

b. 700
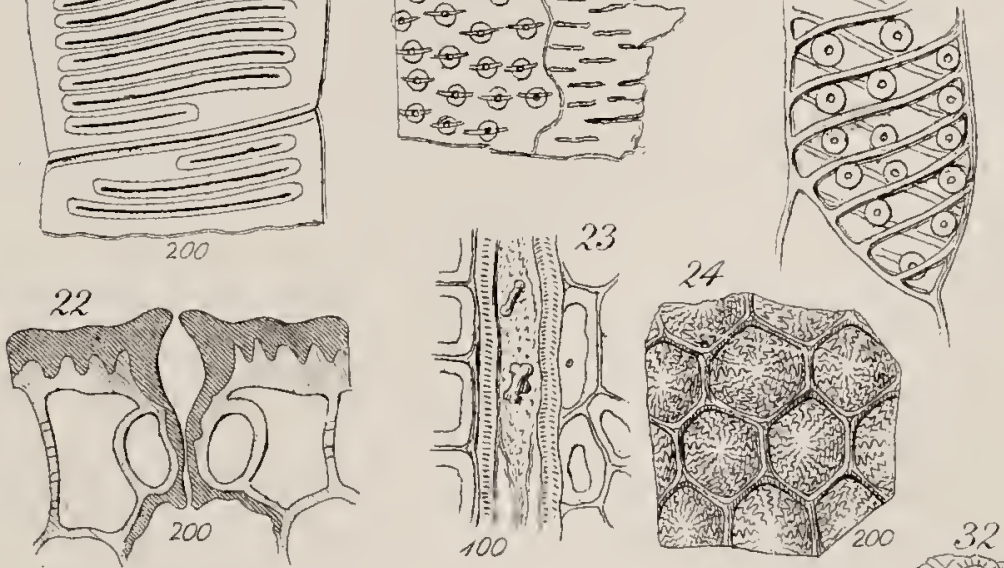

${ }^{20}$
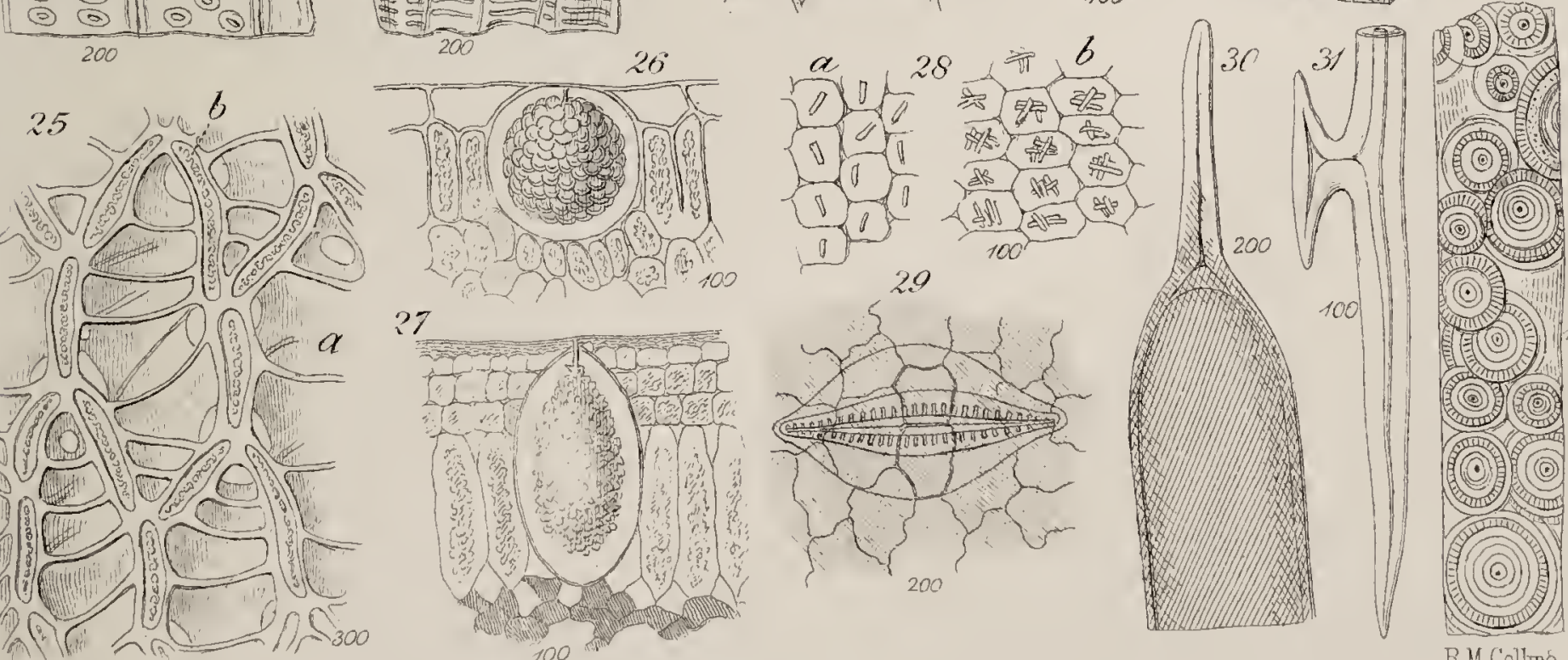

A Fanfrey deI
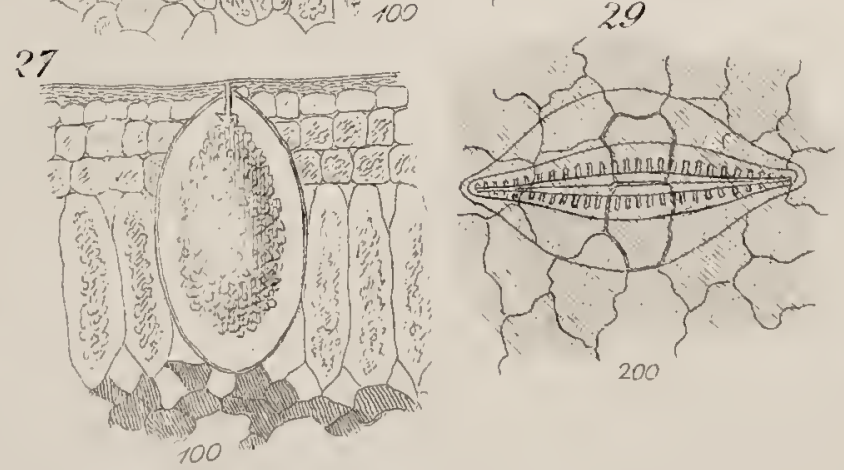

London. John Van Voorst 1871

RM Collirg 



VAN VOORST'S ALPHABETICAL LIST OF BOOKS.

BELL. BRITISH STALK-EYED CRUSTACEA. 8vo, $25 \mathrm{s.}$

-. BRITISII QUADRUPEDS. Second Edition. In the press.

BENNETT. GATHERINGS OF A NATURALIST IN AUSTRALASIA. 8 ro, $21 s$.

BETAN. THE HONEY-BEE. A New Edition by W. A. Munn. Post 8vo, 10s. $6 d$.

BIGSBY. THESAURUS SILURICUS. 4to, 18 s.

BLOOMFIELD'S FARMER'S BOY, AND OTHER POEMS. With Illustrations, foolscap $8 v 0,7 s .6 d$; ; large paper, $15 s$.

BOCCIUS. PRODUCTION AND MANAGEMENT OF FTSH IN FRESH Waters. 8vo,

BONAPARTE. GEOGRAPHICAL AND COMPARATIVE LIST OF THE Birds of Europe and North America. 8vo, 5 s.

BREHM'S BIRD-LIFE. From the German, by LABouchere and Jesse. In Parts, 2s. 6d. each.

BREWER. FLORA OF SURREY. 12mo, with Two Maps, 7 s. $6 d$.

BRIGHTWELL. LIFE OF LINN AUS. Foolscap 8ro, 3s. $6 d$.

BRODRICK. FALCONERS' FAVOURITES. Folio, $£ 22 s$.

BULLER. LETTERS FROM ABROAD. Post 8vo, $7 \mathrm{~s}$.

BURTON. FALCONRY IN THE VALLEY OF THE INDUS. Post 8vo, is. CARRINGTON'S LEPIDOPTERISTS' REGISTER. Complete in 28 Parts, 4 to, $3 d$. each.

CATALOGUE OF BRITISH VERTEBRATE ANIMALS. 8vo, sewed, 2s. tid. CHEIICAL SOCIETY; JOURNAL OF. Annual Subscription $£ 11$ s.

CHURCH. THE LABORATORY-GUIDE, SPECIALLY ARRANGED for Agricultural Students. Second Edition, post 8vo, 5s. $6 d$.

CLARK. BRITISH MARINE TESTACEOUS MOLLUSCA. 8ซo. $15 s$. . LETTERS HOME, FROM SPAIN, ALGERIA, AND BRAZIL. 8 vo, $7 s .6 d$.

CLAUSIUS. THE MECHANICAL THEORY OF HEdT. Translated by Hirst. Sro, $15 s$.

CLERMONT, LORD. GUIDE TO THE QUADRUPEDS AND REP. tiles of Europe. Post 8vo, $7 \mathrm{~s}$.

COUCH. ILIUSTRATIONS OF INSTINCT. Post 8 vo, $8 s .6 d$.

CRICHTON, A NATURALIST'S RAMBLE TO THE ORCADES. Foolscap 8ro, 4s.

CUMMING. THE ISLE OF MAN. Post 8ro, 12s. $6 d$.

CUPS AND THEIR CUSTOMS. Post 8ro, Second Edition, 2s. 6d.

CURRENCY (THE) UNDER THE ACT OF 1844. 8vo, $6 s$.

DALLAS. ELEMENTS OF ENTOMOLOGY. Post 8vo, 8 s. $6 d$.

DODSLEY. ECONOMY OF HUMAN LIFE. 12 Plates, $18 \mathrm{mo}, 5 \mathrm{~s}$.

DOMESTIC SCENES IN GREENLAND AND ICELAND. Second Ed., $16 \mathrm{mo}, 2 s$.

DONKIN. BRITISH DIATOMACE E. In parts, 8ro, 2s. 6d.; Royal 8vo, India plates, $5 s$. ( 2 published).

DOUGLAS. THE WORLD OF INSECTS. $12 \mathrm{mo}$, sewed, $3 \mathrm{~s} .6 \mathrm{~d}$. 
VAN VOORST'S ALPHABETICAL LIST OF BOOKS.

DOWDEN. WALKS AFTER WILD FLOWERS. Foolscap 8ro, 4s. $6 d$. DREW. PRACTICAL METEOROLOGY. Second Edition, foolscnp 8vo, $5 s$. DRUMMOND. FIRST STEPS TO ANATOMY. 12mo, $5 s$.

ELEMENTS OF PRACTICAL KNOWLEDGE. Second Edition, 18mo, 3s. ELIOT AND STORER. A MANUAL OF INORGANIC CHEMISTRY. Crown 8ro, 10s. $6 d$.

ENGLAND BEFORE THE NORMAN CONQUEST. $16 \mathrm{mo}, 2 s .6 d$.

ENTOMOLOGISTS' ANNUAL, 1855-71. Foolscap, 2s. 6d. each.

ENTOMOLOGISTS' MONTHLY MAGAZINE. Nos. 1-86, 6d. each.

EVENING THOUGHTS, BY A PHYSICIAN. Post 8ro. Third Edit. 4s. 6d. EYTON. HISTORY OF THE OYSTER AND THE OYSTER-FISHERIES. 8 ro, $5 s$.

FIELD. THE MOCKING-BIRD AND OTHER POEMS. Feap 8ro, 5 s. FLY-FISHING IN SALT AND FRESH WATER. 8ro, $7 s .6 d$.

FORBES. HISTORY OF BRITISH STARFISHES. 8vo, 15 s.

FORBES AND AUSTEN. NATURAL HISTORY OF THE EUROPEAN Seas. Foolscap 8vo, 5 s.

FORBES AND HANLEY. HISTORY OF BRITISH MOLLTSCA AND their Shells. 4 rols. 8 ro, $£ 610$ s.; Royal 8ro, with the Plates Coloured, $£ 13$.

FRANKLAND. LECTURE-NOTES FOR CHEMICAL STUDENTS. Second Edition, post 8vo, vol. i. (Inorganic) $4 s$.

GARNER. FIGURES OF INVERTEBRATE ANIMALS. Royal 8vo, 5 s. NATURAL HISTORY OF THE COUNTY OF STAFFORD (with Supplement), 8ro, 10s.

GODMAN. NATURAL HISTORY OF THE AZORES. 8ro, 9s.

GOLDSMITH. VICAR OF WAKEFIELD. Illustrated by MulREADY. Second Edition, square 8 ro, $10 s .6 d$.

GOODSIR. AN ARCTIC VOYAGE. Post 8ro, 5s, 6d.

GOSSE. AQUARIUM. Post 8ro, Second Edition, $17 s$.

2s. $6 d$

BIRDS OF JAMAICA. Post 8 ro, $10 s$.
BRITISH SEA-ANEMONES. 8 ro, $21 s$.

- CANADIAN NATURALIST. Post 8ro, 12

DEVONSHIRE COAST. Post $8 \mathrm{vo}, 21$ s.

- - MANUAL OF MARINE ZOOLOGY. 2 vols. fcap 8vo, 7s. $6 \mathrm{~d}$. each. OMPHALOS. Post 8ro, 10s. $6 d$.

. TENBY. Post 8ro, $21 \mathrm{~s}$.

GREENE. THE INSECT-HUNTER'S COMPANION. Fcap 8vo, 2nd Ed., 1s. 6 d.

GRAY'S BARD. With Illustrations; uniform with the Elegy, post 8vo, 7 s.

- ELEGY IN A COUNTRY CHURCHYARD. With 33 Engravings, post $8 \mathrm{ro}, 9 \mathrm{~s}$; Polyglot Edition, 12s.; a small edition, foolscap 8ro, $2 \mathrm{~s} .6 \mathrm{~d}$.

GREG AND LETTSOM. MANUAL OF BRITISH MINERALOGY. 8vo,15s.

GRIFFITH AND HENFREY. MICROGRAPHIC DICTIONARY. Third Edition. In preparation: in parts at $2 s .6 d$. 